\title{
La Metáfora Visual en las Cartografias del Cuerpo
}

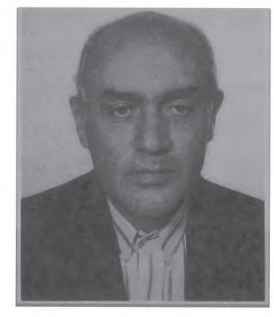




\begin{abstract}
The space of representation in pictorial and photographic portraits is crucial for the structure of bodily expressiveness. Considering the role for painters and photographers in stimulating meaningful expansions, this essay is an attempt to identify an iconographic metaphor as a result of the interpenetration of two different plastic figures and to analyse its surrealistic attachments to an androgynous configuration.
\end{abstract}

\title{
Key words
}

portraits, iconographic, metaphor, epistemological metaphor of Surrealism.

\section{Resumo}

O presente trabalho é uma tentativa de identificar, a partir da representação da corporalidade em retratos pictóricos e fotográficos, um tipo de metáfora resultante da interpenetração de duas figuras plásticas diferentes, e, ainda, analisar as relações surrealistas que tal tropo mantém com uma configuração andrógina.

\section{Palavras-chave}

retrato, metáfora iconográfica, metáfora epistemológica do Surrealismo. 
E

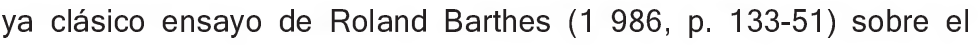
arte pictórico de Arcimboldo, si lo releemos ${ }^{1}$ teniendo en cuenta ideas recientes acerca de la metáfora visual, ${ }^{2}$ plantea algunas cuestiones retóricas que, en virtud de las sutilezas semántico-expresivas de los fenómenos poéticos, requieren atención. Para el famoso semiólogo, buena parte de los cuadros del pintor italiano obedece los principales parámetros deí

1. El texto del presente trabajo tiene sus raíces en los presupuestos de relectura de la metáfora arcimbolesca formulados en la ponencia que, con el título de "Arcimboldo e la metáfora visiva”, presenté en el $V^{0}$ Congresso deli 'Associa^ione Internationale di Semiótica Visiva, celebrado en Siena, Italia, de 24 a 28 de junio de 1998. Deseo, en primer lugar, expresar mi gratitud a la Fundación Capes, pues sin su auxilio habría sido imposible mi participación en el evento y al CNPq por la beca de productividad académica que me concedió, ya hace más de tres años, para investigar los aspectos poéticos de las imágenes de la contemporaneidad y, en segundo lugar, advertir que esta primera versión del trabajo que publico en Significação tiene, asumidamente, un cariz erudito y se destina a lectores que no sean amantes del apresuramiento. Por eso, siempre que me pareció indispensable, coloqué los presupuestos teóricos fundamentales e informaciones adicionales en forma de notas, evitando paráfrasis del pensamiento de otros autores, manera más transparente y responsable de respetar lo ajeno, de dialogar, casi en silencio, con textos de que, cuando me fue posible, mantuve, en los fragmentos citados, la lengua en que originariamente fueron escritos. Claro que el lector con conocimientos de semiótica, podrá leer el trabajo sin tales auxilios. Agradezco también de manera muy especial a Fernando Scavone por la cuidadosa reproducción técnica de las imágenes.

2. Me refiero, principalmente, a los modelos construidos en el libro Traite dú signe visuel, del Groupe (I (1992) .Y como pienso también en la cartografía del cuerpo, confieso mi preferencia por un librito que me fascina porque su autor, ya en la introducción, 
género ${ }^{3}$ retratístico y pone de manifiesto el arte de manipular dispositivos para singularizar configuraciones en que se congregan, ingeniosamente, componentes de varios sistemas sígnicos. El uso artístico de esa diversidad de códigos determina, por supuesto, modalidades expresivas sobre las cuales cada época hace recaer gustos y preferencias. Tomando por ejemplo el lenguaje de la gestualidad, desde el final de la Edad Media no solamente nobles y autoridades eclisiásticas eran los protagonistas de un ritual de poses $^{4}$ legitimador de los retratos, sino que también mercaderes, artesanos, banqueros y artistas habían conquistado semejante privilegio.

susurra: "In discussing physics as metaphor, I suggest that the metaphoric act transcends language and vitalizes creativity in science. It is generally acknowledged that scientists often use creative analogies and comparisons to extend theories and even to make new ones. Modern elementary particles are extensions and elaborations of the Greek átomos, and William Harvey found in the centralized sun of Corpernicus a model for the heart as the center of the circulation of blood. But I go beyond these relations in form alone and suggest that scientists ( and indeed all who possess creative consciousness) conjure like the poet and the shaman, that their theories are metaphors which ultimately are inseparable from the physical reality, and that consciousness is so integral to the cosmos that the creative idea and the thing are one and the same" (JONES, 1983, p. 4-5).

3. Nome párece oportuno discutir en esta ocasión la diversidad de conceptos utilizados para definir la idea de género. Mi única intención aquí es entenderlo como si fuese algo semejante a lo que Eric Landowski cree que sea la opinión pública: "De cet ensemble de relations se dégagent finalement deux types essentiels d'interventions de l'opinion publique, les unes visant l'action des 'héros', les autres les convictions de l'auditoire. De ce point de vue, l'opinion n 'est pas, comme on le dit souvent, 'manipulée' - elle est au contraire la grande manipulatrice" (LANDOWSKI, 1989, p. 32). Por lo tanto, el género, inserido en ese contexto, se presenta como un concepto manipulador que sirve no sólo para reunir en un conjunto universo objetos culturales que comparten propiedades comunes, sino también como un subcódigo que conduce a los receptores de esos objetos a significados previamente establecidos: esto es un retrato, esto es un paisaje etc

4. Según el diccionario de la Real Academia, pose es un galicismo utilizado con frecuencia para significar posición, postura o actitud. En el contexto de este trabajo significa simultáneamente todo eso y algo más. La pose, entendida como postura o actitud, remite a dos sistemas de signos comprometidos estrechamente con las cartografías del cuerpo: el de la gestualidad y el de la proxémica - algunos autores escriben prosémica, pero a mí me parece ser proxémica la grafía correcta. La gestualidad ordena, en la representación del cuerpo, vólúmenes y órganos confiriéndoles un determinado significado y la proxémica lidia con las distancias y los trayectos. Pero, además de eso, la pose, en cuanto actitud, proviene, en el caso de la pintura, de la paralización del movimiento en un punto 


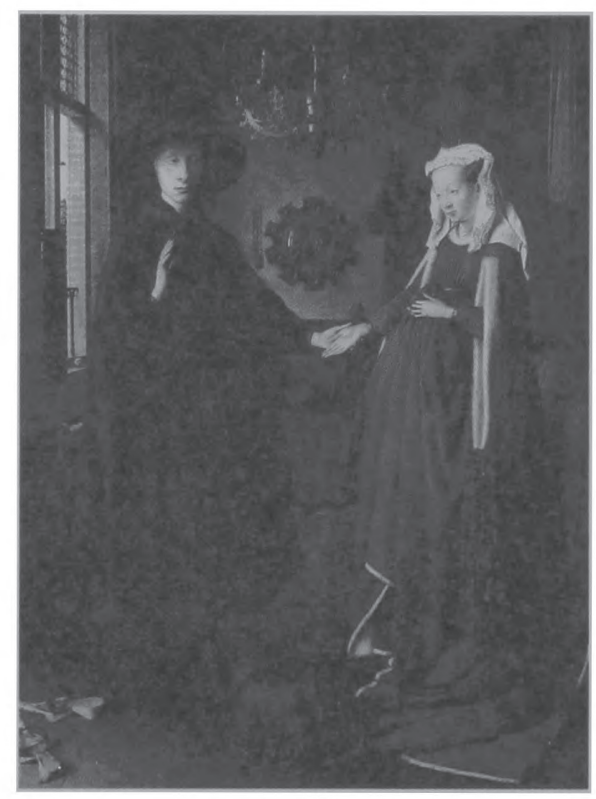

Durante los siglos XV, XVI y XVII, muchos de los gestos plasmados en cuadros que, aun en nuestros días, despiertan admiración, se revisten de un bisemismo singular. En El casamiento de Giovanni Arnolfini, de Jan Van Eyck, el entrelazamiento de las manos denota el afecto de la pareja

punto estratégico. El concepto de tableau de Diderot valora ese principio. A ese respecto, Burgin observa: "As the painter of "histories" had to show in a single instant that which took time to unfold, then that instant had to have a singularly privileged position within the total action. It was therefore recommended that the moment selected by the painter for visualization should be the peripateia, that instant in the course of an action when all things hangs in the balance" (Burgin, 1989, p. 86). Resulta curioso el hecho de que Aaron Scharf, al hablar de las poses para retratos, nos cuente la historieta de Topaz, un mono brasileño que decide ir a París para estudiar pintura y termina entendiendo que el arte exige imaginación y no imitación de posiciones o actitudes; mas, reconociendo su falta de tino artístico, Topaz remedia esa situación comprando "una cámara de daguerrotipo y vuelve a su tierra natal, donde funda el primer estudio de retratos fotográficos, lo cual le permite actuar como un auténtico hijo de la madre naturaleza" (Scharf, 1994, p. 50). Yo, particularmente, estoy convencido que Topaz, a pesar del gran éxito que tuvo con "la buena sociedad de la jungla", terminó aprendiendo que el secreto poético de las poses fotográficas depende, también, de la peñpateia. 
y reproduce en pormenor la iconografía del dextrarum junctio, impregnándolo, consecuentemente, con las connotaciones que tal ademán tenía en el culto mariano. Las velas, el candelabro y las frutas matizan, como obervó Schneider, ${ }^{5}$ aspectos del marianismo.

Mas la opacidad que gana la representación de las cosas en esa especie de cuadros aleja los signos de su referencialidad inmediata. En cuanto resultados de un desmenuzamiento, por decirlo así, del sistema denotado en que la costumbre implanta los valores y la identidad cotidiana de los objetos, tales contenidos sobreviven a esos destrozos semánticos e instauran, reorganizándose con el auxilio eficaz de ciertas figuras retóricas, procesos de significación más densos. Así, si nos detenemos en el sistema de los objetos, el espejo convexo, fijo en la pared del fondo de la habitación de los Arnolfini, no sólo plantea un intrincado problema de enunciación, ${ }^{6}$

5. "The burning candle in the chandelier, a wedding candle, cites traditional Annunciation iconography. It underlines the Mariological character of the painting. Addressed specifically to women, Mariolatry was a constitutive factor in fifteenth-century conjugal mores. The apples lying on the window-sill are allusion to the Fall and a warning against sinful behaviou "' (SCHNEIDER, 1994, p. 35).

6. "The painting is a visual record of the event; indeed it even acts as a wedding certificate, since it documents the artist's attendance and consequent witness of the ceremony in the inscription on the far wall ('Johannes de Eyck fuit hid). Along with a second witness, van Eyck is reflected in a convex mirror on the same wall. The mirror enlarges the room and is framed by ten painted scenes from the Passion" (SCHNEIDer, 1994, p. 33). Mucho se ha escrito sobre la influencia de esta obra de van Eyck en Las meninas, de Velázquez, uno de los cuadros más complejos, como se sabe, en lo que se refiere a los procesos de enunciación. José López-Rey admite que el pintor sevillano conocía la obra de van Eyck, mas, amparándose en detalles enunciativos de cada uno de los lienzos, afirma que la composición obtenida por Velázquez "is essentially different from Van Eyck s, where the convex mirror on the rear wall reflects not only the two men coming in through a door at the opposite end of the room, but also, and equally distinctly, the other three walls and the back view of the two sitters, none of whom is related by action or gesture to the space lying out of the picture frame (cat.n. ${ }^{\circ}$ 124). Grouped together, indeed, they centre about themselves the space of the interior, which the reflection in the mirror makes the more definite. This has little in common with Velázquez composition [...]" (LOPEZ-RKY, 1996, p. 214). En la recreación que Fernando Botero hace del lienzo de van Eyck, es posible encontrar variables que ayudan a ver otros aspectos del problema enunciativo (ANTOINE, 1995, p. 13-7).

Significaçâo $13 \cdot 80$ 
sino que configura, también, una especie de metáfora speculum sine macula - cuyo destino, en términos poéticos, es el de establecer una relación posible entre la castidad de la novia y la pureza de la Virgen.

Al comentar el retrato de Carlos $\mathrm{V}$ que actualmente se encuentra na Alte Pinakothek, de Munich, Panofsky admite la existencia de retratos autóno-

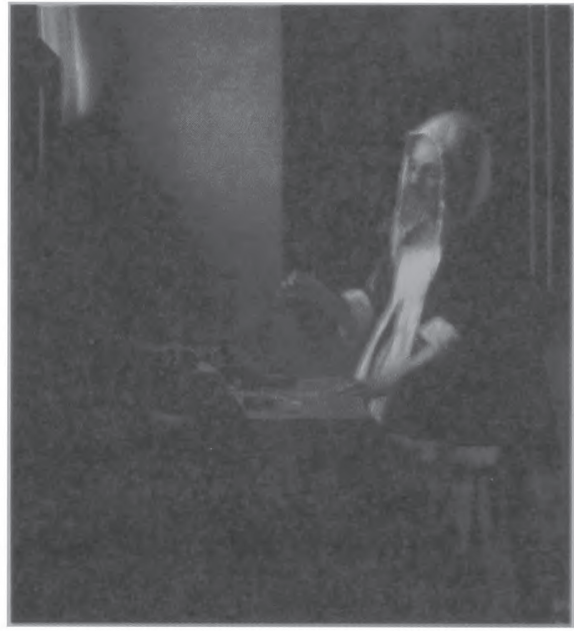
$\operatorname{mos}^{7}$ cuando, en este género pictórico, los objetos no se comprometen, a lo que parece, con otros valores a no ser los de uso. La silla en que está sentado el emperador es sencillamente una silla, o sea, un objeto cuyo valor de uso no permite otras interpretaciones. Esa liberación de los utensilios tiene, sin embargo, en el género retratístico, algunas particularidades notables. En el caso espécifico de Mujer pesando oro, varios de los principales autores ${ }^{8}$ que analizan el famoso cuadro de Veermer oscilan entre la interpretación de la balanza como metáfora de un equilibrio transcendental y la interpretación de la balanza como un objeto doméstico que remite a la interioridad de la casa y de la mujer. ${ }^{9}$

7. "Si ce portrait de Charles Quint dans son fauteuil constitue le premier exemple de portrait autonome, ni allégorie ni oeuvre de cérémonie (par opposition aux monnaies, sceaux, enluminures de livres, portraits alégoriques, tombeaux, monuments publics ou portraits de groupes), qui représente le sujet assis mais en pied, de même le portrait de Charles Quint sur son cheval constituit le premier portrait équestre autonome - ni allégorique, ni oeuvre de cérémonie - de l'histoire de la peinture" (PANOFSKY, 1990, p. 121).

8. Me refiero a críticos como John Michael Mond as (1989), Arthur K. Wheelock (1995), Christopher Wright (1976) y Eugene R. Cunnar (1990).

9. Los siguientes fragmentos de Veermer and the art of painting ilustran esa posición: "The woman s white cap and blue morning jacket contrast with the. dark painting. Her figure 
No se debe rehuir la idea de que estos retratos tienen también fuertes vínculos con ese otro género pictórico que se manifiesta en los llamados interiores holandeses. En este tipo de obras, lo que predomina es la representación de gestos de lo cotidiano, de personajes absorvidos en quehaceres domésticos y, en ese caso, los objetos quedan liberados de sus compromisos alegóricos. Libres, aparentemente, de lo alegórico y hasta de las circunstancias de lo histórico, ${ }^{10}$ las cosas pintadas se abren

is aligned with the central axis of the Lastjudgment, and her head lies at the middle of its compisition, directly beneath the oval mandorla of the Christ in majesty. Her right hand, holding the balance, coincides with the lower corner of the frame. The position of her head and the central gesture of her hand are thus visually bound with the hast judgment, and a seeming moment of quiet contemplation becomes endowed with symbolic associations. [...]. 'The visual juxtaposition of the woman and xheLastjudgmentis reinforced by thematic parallels: to judge is to weigh. [...] Nevertheless, the woman's pensive response to the balance she holds suggests that her act of judgment, although different in consequence, is as considered as that of the Christ behind her. Her mood is in sharp contrast to the violent scene of salvation and damnation in the Lastjudgment. Her serene countenance belies no fear of the consequences of the final day of judgment. [...]. Most interpretations of this painting have focused on the act of weighing and have assumed that the pans of the woman's balance contain certain precious objects, generally identified as gold and pearls. Consequently, throughout ist history the painting has been alternately tided Goldweigher or Girl Weighing Pearls. Behind these diverse interpretations of the painting lies considerable confusion as to whether the woman is weighing pearls, gold, weights, pearls versus gold, jewels, or whether she is merely balancing the scales. Questions concerning the nature of her action are closely interwined with the broader question of the symbolic intent of the juxtaposition of the woman and the painting of theLastjudgmenf' (WHEEiocti, 1995a, p. 97-8).

10. Claro que al historiador del arte le interesa tener informaciones precisas sobre el momento en que un determinado objeto entra en el ámbito de lo cotidiano $\mathrm{y}$, ciertamente, los significados que tal información fornece pueden ser de mucha utilidad para quien se dedica a una interpretación de los valores diacrónicos y sincrónicos del sistema de los objetos representados en un cuadro. Prueba de ello la encontramos en el capítulo IV, que tiene por d'tulo "Réflexions sur le temps", del libro Le Titien. Questions d'iconologie. Véase, para tener tan sólo una idea del asunto, lo que nos dice Panofsky en este fragmento extraído del mencionado capítulo: "Je comencerai la discussion sur ses réflexions de peintre sur le temps, en faisant d'abord remarquer un fait qui, pour n'être pas évident, n'en est pas moins significatif à mon sens: dans sept, peut-être huit des portraits du Titien - en commençant par celui d'Eleonora, duchesse d'Urbino, la fille d'Isabelle d'Este (fig. 93), et en passant par le triple portrait de Pauli III et de ses petits-fils apparaît un objet extrêmement rare dans les autres portraits de la Renaissance: une pendulette. $^{1}$

Significaçôo $13 \quad 82$ 
paso hacia los recintos tímicos a que se alude en la representación pictórica y que constituyen, a lo que parece, una suerte de diagnóstico de la imaginada psicología de los personajes. Se sabe que el interés científico y filosófico por cuestiones de psicología crece especialmente en Italia a partir de la segunda mitad del Quattrocento. Las interpretaciones de la expresión corporal podían ser útiles para conocer el carácter de un comerciante y, consecuentemente, se podrían transformaren indicios que facilitaban o dificultaban la realización de un buen negocio. Sin embargo, en lo que se refiere a la obra de Vermeer, esos rasgos adquirían connotaciones más transcendentales, aunque la liberación de los objetos de compromisos alegóricos y la carnalidad de los personajes engendrasen fuertes simulacros de realismo. Ese matiz ya aparece de manera bien acentuada en la obra de van Eyck, pues, como observa Schneider, este pintor reproduce "the texture of his sitters skin in microscopic detail", procurando, con eso, acercarse al nominalismo filosófico de su tiempo, captar la "contingente fisicalidad" de los individuos retratados.

Lo que sin duda se consagra en esa tradición retratística es una especie de invariable instituida por la relación complementaria entre la corporeidad y la ambiencia, sea ésta constituida por un espacio habitacional recluso o por un paisaje natural abierto, frecuente, como se sabe, en la pintura

Comme la plutart des attributs, celui-ci est porteur de significations multiples. Cette version 'miniaturisée' de l'horloge mécanique - innovation datant elle-même du début du XIVe siècle - était d'apparition assez récente (environ 1440) et de prix élevé à l'époque. On peut donc considérer qu'il s'agissait d'une sorte de symbole de statut social, comme la clochette à main du Portrait de Uon $X$ et ses neveux de Rafhaël (fig. 78); mais la pendulette a également des implications morales.

Henry Suso avait intitulé l'un des ses traités les plus populaires Horologium sapientiae (en français Horloge de Sapience ${ }^{2}$ ). En raison de son mouvement parfaitement régulier (nous parlons encore aujourd'hui de 'régularité d'horloge') l'horloge mécanique, qui mesurait encore plus d'un mètre cinquante de haut, était pour Christine de Pisan (13631431) un symbole spécifique de la tempérance; et à partir du milieu du XVe siècle et jusqu'à Peter Bruegel, la pendulette devient, sur les supports les plus variés, et en particulier dans la sculture funéraire (fig. 92)\ un atribut de cette vertu dans tous les médias imaginables" (PANOFSKY, 1990, p. 130). 


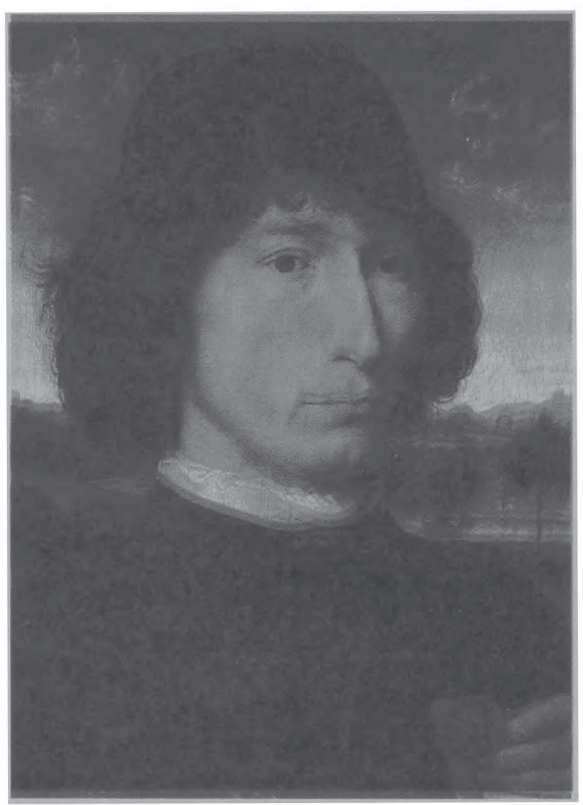

italiana de este género desde el Renacimiento. El conocido cuadro de Hans Memling titulado Hombre con moneda romana, inspirado, sin duda, en obra de Sandro Boticelli, ${ }^{11}$ muestra esa relación a través de una combinatoria en la que un paisaje campestre con río, cerros y árboles se reviste de un bisemismo, semejante al que se manifiesta en los objetos del ambiente casero de los cuadros de Vermeer, que sirve para representar no sólo el mundo de la naturaleza sino también aspectos interiores de la personalidad del individuo retratado. En la obra de Memling, los cisnes que se deslizan sobre el río evocan, recuérdese el motivo de la tristeza

11. Me refiero al cuadro en que se representa a un joven que mantiene entre las manos una medalla y del cual Ronald Lightbown, en su hermoso estudio sobre el pintor italiano, nos dice: "Boticelli's other surviving early portrait in an open setting is the mysterious picture in the Uffizi of a young man holding a medal of Cosimo de' Medici (plate 21). An ambitious essay in a manner ultimately Flemish, it seems to have been painted around 1474-75, since it shows a subtler modeling than the bold, smoothly rounded oval of Boticelli's first heads" (Lightbown, 1989, p. 54).

Significagão $13 \quad 84$ 
Rendaría de su canto, algo que despierta en la memoria de un alma ¡vota motivos dramáticos de la Pasión de Cristo. Eso pone en evidencia, gún la lectura que varios historiadores del arte han hecho de esta tela, le el paisaje refleja el estado mental y emocional del personaje retratado.

Arcimboldo, con sus "teste composte", introdujo alteraciones de monta i las combinatorias proxémicas ${ }^{12}$ que plasman la expresións pictórica ; las relaciones entre los personajes y las cosas. En los retratos del tista italiano, los elementos de la naturaleza o los objetos del ambiente eservan la función de compleentar los significados individúaadores de las personas represendas. Pero, vistos en el contexto presivo del cuadro, esos mismos ementos u objetos, depués de iber sido sometidos a un radical oceso de desplazamiento, pasan integrar las formas significantes sponsables por la configuración i que se plasma, analógicamen, el rostro o el cuerpo entero de s personajes retratados. Así, en bibliotecario, para citar un ejem-

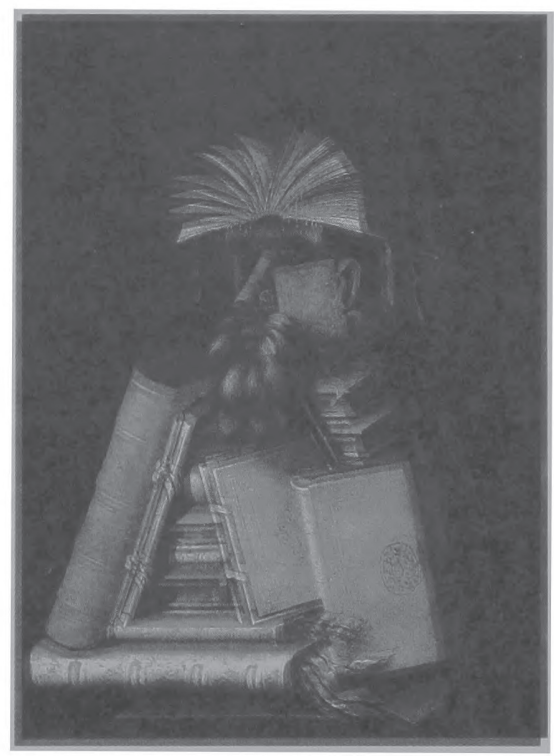

En la nota 11 del capítulo $\mathrm{V}$ del hermoso libro Beyond culture, Edward T. Hall nos dice que la proxémica "refers to man s use of space as an aspect of his culture: i.e., conversational distance, planning, and use of the interior space, town layout, and the like" (HALL, 1976, p. 218). Los cuadros que Arcimboldo dedica a las cuatro estaciones del año realzan, de modo bastante intrincado, las relaciones entre el espacio y el tiempo. Claro que, como observa Kaufman (1987, p. 99-100), para comprender algunas de las bases ideológicas de esas pinturas es necesario revisar el sistema de pensamiento en que se inspiran, la conexión de los lienzos con los poemas de Fonteo y, aún, el papel que desempeña el cuerpo político de los Habsburgo en esas y otras telas del artista. Pero, por otro lado, es innegable la existencia en todas esas obras de una organización espaciotemporal cuya hondura significativa puede ser estudiada de manera apropiada 
pío, los libros, tras de abandonar los anaqueles de una estantería, conquistan una disposición que les permite simular la anatomía de la cara y los hombros de una supuesta persona que trabaja en una biblioteca.

Hay que reconocer, por consiguiente, que el hecho de que las hojas de un libro abierto imiten la melena de un bibliotecario no sólo representa una ruptura de la invariable determinada por la relación complementaria entre la corporeidad y la ambiencia, sino que el proceso de desplazamiento instituye, también, un proceso de condensación en el que cohabitan rasgos estéticos y oníricos. Pontus Hulten (1987) propone una lectura de la obra de Arcimboldo fundamentada en tres maneras interpretativas diferentes: la primera, inspirada en el fascinio que ejerce sobre el espectador de la magia de la pintura de este artista, sería la que se engendra en una "amusing curiosity"; la segunda, conforme a datos acerca de la vida intelectual de la corte de los Habsburgo, estaría montada sobre las alegorías del Imperio y de la Ciencia; y la tercera tendría como fuente las premisas de una transformación metafísica. Hulten reconoce, sin embargo, que esas tres maneras de interpretar no satisfacen la inquietud del lector de nuestro tiempo, pues hay que admitir que la pintura de Arcimboldo se relaciona no sólo con lo racional, sino con lo inconsciente también. Aun así, una cosa es clara para este autor:

Arcimboldo s pantheistic concept of the world - in which all beings are treated with equal reference and attention - is certainly in contradiction to the rather dry, academic, and mechanical presentation of the ancients universe created by the mannerists. Thus Arcimboldo can be thought of as anti-mannerist (HULTEN, 1987, p. 31).

a través de la proxémica, ya que "one of the most basic organizing systems of life, for all situational behavior has a temporal and spatial (proxemic) dimension" (HALL, 1976, p. 119).

Significado $13 \cdot 86$ 
Tal vez por oponer el embrujo de las incógnitas vitales a lo mecánico, esa cartografía de los retratos arcimbolescos que dibuja los contornos de exuberantes condensaciones en que el cuerpo representado, fantástico mapa de microcósmicas maravillas, se integra con las cosas del mundo, reúna en su pictórica estructura algo de ese misterio onírico al que se refiere Lyotard cuando atisba la extensión corporal como algo que va más allá de las dimensionens mundanas y que exige

prendre èn considération le fait que nous dormons en rêvant, et que justement la connaturalité du corps et du monde est suspendue par une immobilité qui $n$ a pas seulement pour fonction d'élimier le monde, mais pour effet de prendre pour monde le corps [...]

(Lyotard, 1974, p. 275-76).

Las imágenes construidas de esa manera reviven sentidos poéticos enmarañados en un denso contexto estético, observable, por ejemplo, en las prestidigitaciones alegóricas ${ }^{13}$ que diseminan prodigios, derroches de fantasía en ese laberinto de imágenes que se aglomeran en Vertumnus.

Además de eso, tales imágenes convierten, como ya observó Barthes, el entramado de la pintura arcimbolesca

en una auténtica lengua, la dota de una doble articulación: la cabeza de Calvino se puede descomponer, primero, en formas que son ya objetos con un

13. "The portrait's intention is even more pronounced in Arcimboldo's Vertumnus. The god of vegetation referred to here is Rudolf II who, according to Lomazzo, had asked the artist to make something amusing for him. The protean versatility which mythology ascribed to Vertumnus is attributed in this act of homage to the Emperor, with his vast variety of different fields of influence and activity. At the same time, the painting refers us to a principle of aesthetic metamorphosis which Comanini explains in 257 lines of verse in his somewhat verbose 'Canzoniere' (1609)” (SCHNEIDER, 1994, p. 123). 


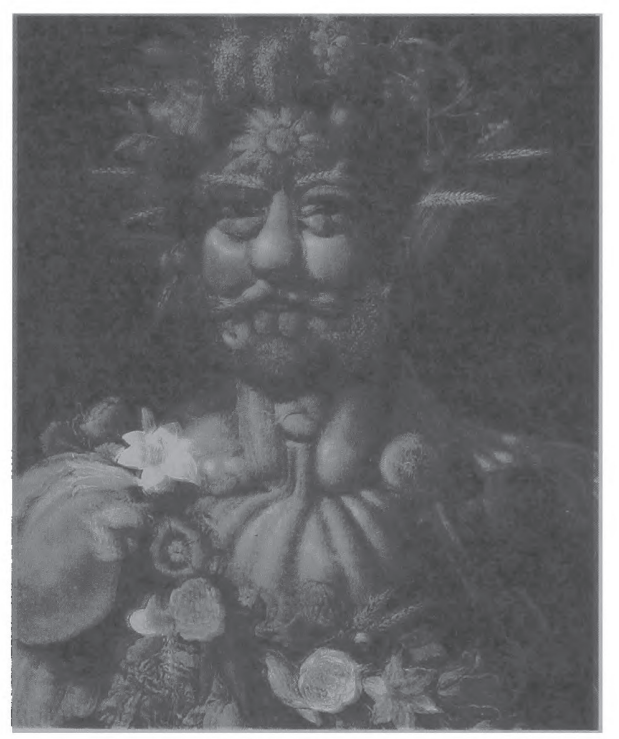

nombre, es decir, en palabras: una carcasa de pollo, una mano de mortero, una cola de pescado, legajos escritos; estos objetos, a su vez, se descomponen en formas que, por sí solas, no significan nada; volvemos a encontrarnos con la doble escala de las palabras y los sonidos. Es como si Arcimboldo modificara las reglas del sistema pictórico, lo desdoblara abusivamente, hipertrofiara su virtualidad significante, analógica, y produjera así una especie de monstruo estructural, origen de un malestar sutil (por lo intelectual), más penetrante aún que si el horror procediera de una simple exageración o de una simple mezcla de elementos: el hecho de que todo significante, a dos niveles, es lo que hace que la pintura de Arcimboldo funcione como una negación algo terrorífica de la lengua pictórica (BARTHES, 1986, p. 138).

Significagáo $13 \cdot 88$ 
Las metáforas que ensartan las relaciones de semiosis de semejante entramado sígnico son, según Barthes, generalmente sensatas. $O$ sea, que entre los dos términos que constituyen la comparación en que se basa la figura metafórica subsiste un rasgo común, un eslabón, una cierta analogía: los dientes, por ejemplo, se parecen a guisantes en su vaina, la nariz se parece a una mazorca, por su forma oblonga y abombada. En fin, la metáfora arcimbolesca es, por así decirlo, de dirección única: nos convence de que la nariz se parece naturalmente a una mazorca, porque nadie diría, de manera natural, que la mazorca es una nariz. Pero, parafraseando el pensamiento de Barthes, la metáfora arcimbolesca también es audaz: desmembra objetos familiares para producir otros, nuevos, extraños, gracias a esa auténtica imposición que es el trabajo del visionario. Es posible que la audacia no esté en estas metáforas improbables, sino en las que podríamos llamar desenvueltas, esto es, en las que resultan de cambiar el objeto de lugar: es lo que ocurre cuando Arcimboldo, en $L$ Acqua, sustituye los clientes del personaje que representa el agua por los dientes de un escualo. La metáfora aquí es una tautología: los dientes son los dientes, lo que hubo fue sólo un cambio de lugar, un cambio de contexto.

Tales ¡deas permiten afirmar que la visión semiótica de Roland Barthes, al igual que la metáfora arcimbolesca, es, por un lado, sensata y, por otro, audaz. ${ }^{14}$ Sensata cuando, basándose en el modelo de la dupla articulación, establece relaciones entre la pintura de Arcimboldo y la lengua. Audaz cuando nos dice que el pintor italiano trabaja como si modificara las reglas del sistema pictórico, como si lo desdoblara abusivamente e hipertrofiara su virtualidad significante. Se sabe que la doble articulación fue, durante mucho tiempo, la condición indispensable para conferir a lo pictórico las propiedades de un lenguaje y que mucha

14. Hal Foster, con perspicacia, destaca, en el primer capítulo de su libro The retum of the real (1996, p. 1-34), el papel de las audacias críticas (aunque el autor no use este término) en las tareas de valorar y revalorizar los significados de una obra de arte. 
tinta se derramó sobre esta cuestión. ${ }^{15}$ La virtualidad significante, en cuanto audacia semiótica, se conecta a problemas más complejos de cuya solución depende, en buena medida, el poder rescatar aspectos fundamentales de la relevancia de la heterogeneidad ${ }^{16}$ en los textos no verbales. Por eso, si la sensatez hace pensar en la posibilidad de existencia de lexemas pictóricos o fotográficos, la virtualidad del significante no verbal nos conduce a otros planteamientos. Específicamente al que resulta de la imbricación de elementos de diferentes sistemas actualizados en un mismo espacio expresivo.

No cabe duda de que esas dos posturas afectan la constelación de presupuestos con los que trabaja la semiótica europea. Puede decirse, pensando en la manifestación, que, en la Sémantique structurale(1966),

15. Aun en días más cercanos, esa sensatez pasó a ser vista con otros ojos, como se puede constatar en el libro Cinéma etproduction de setis, principalmente en el capítulo $3^{\circ}$, titulado "Recherches sur les unités élémentaires du langage cinématographique. Approche en termes d'ardculadons" (ODIN, 1990, p. 61-90).

16. En la perspectiva de la semiótica europea de la Escuela de Tartu, el término heterogeneidad significa que en un texto visual se manifiestan varios sistemas sígnicos. Así, por ejemplo, en una imagen pictórica se estrutura el sistema de la forma, el del color y el de la textura, para no citar otros.Cada uno de esos sistemas proyecta en el texto sus unidades, lo que quiere decir que una metáfora puede manifestarse en el sistema de la textura y no necesariamente en el de la forma. Todo eso le confiere a la metáfora visual una gran complejidad. En la retórica del Groupe (I, un texto puede presentar un grado zero, esto es, sentido denotado de los signos, caracterizable como general o local. La ruptura de ese grado es responsable por la producción de efectos poéticos $y$, siendo así, parece coherente admitir que un retrato de Arcimboldo, fiel al compromiso de reproducir con verosimilitud la configuración de un rostro, provoca, a primera vista, una fuerte impresión de realidad, o sea, una imagen en la que el grado zero general se ofrece al espectador sin ambages. Pero a medida que la mirada se fija en determinados lugares del cuadro, el espectador empieza a notar que las imágenes que se manifiestan en esos lugares se desvían del grado zero local, provocando, por consiguiente, rupturas de sentido cuyas modalidades sobredeterminan, en muchos casos, el surgimiento de la metáfora. Sin duda, esas rupturas afectan los significados del grado zero general, mas, de manera precisa, alteran los contenidos del grado zero local y tales alteraciones pueden manifestarse a través de las unidades significantes del sistema de la forma o del sistema de la textura (o de cualquier otro sistema: gestualidad, vestuario, etc.). Esas particularidades plasman, por supuesto, la complejidad semiótica de las metáforas visuales a la que aquí me refiero.

Significagóo $13 \quad 90$ 
Greimas trabaja a partir de la premisa de que los semas se acurrucan, por decirlo así, en la completud de nido que toman los signos en sus formas lexemáticas. Sin embargo, en De / 'imperfection (1987), la aparente estabilidad de la semiosis adquiere, en el "nuevo" pensamiento greimasiano, otros alcances, ya que las partículas de sentido, agitadas por las energías de una realidad más profunda, producen irradiaciones capaces de sobrepasar las fronteras - arbitrarias igual que todas las fronteras - del significante estético para alojarse en las entrañas del sujeto que, en cuanto destinatario, el texto atrapa. Porque, concordando en este punto con Raúl Dorra, Greimas, en su último libro, describe el hecho estético a la manera de

un acontecimiento que tiene lugar en la conciencia del sujeto, como una especie de accidente cuya irrupción introduce un desvio o una fractura y al mismo tiempo propicia una apertura sobre la plenitud del sentido. Ese accidente, que convierte al sujeto en sujeto pasional, traza también su camino sobre el cuerpo: la temperatura aumenta, la respiración se modifica. Pareciera que la experiencia estética - y todo aumento de la tensión afectiva - no puede realizarse sino haciéndose lugar entre la entrada y la salida del aire que significa la vida (DORRA, 1997, p. 64).

En Sémiotique du visible (1995), Fontanille afirma que, para el Greimas de la semiótica narrativa, la intencionalidad se lee a posteriori, siendo que para el Greimas de la semiótica estética - mejor sería decir poética -, la intencionalidad tiene su fuente en la imperfección del ser. ${ }^{17}$ Por otro lado,

17 Fontanille, citando Husserl, alude a la idea de que la intencionalidad se vincula a la incompletud y a la desilusión: "c est á dire á un décalage sensible entre la manifestation offerte et celle qui a été attendue” (Fontanille, 1995, p. 7-8). 
Ignácio Assis Silva (1995, p. 34-5) ecuaciona atinadamente esta cuestión al considerar que la relación entre la figuratividad profunda y la de superficie, denominada figurativización, instituye un duplo juego: el de Eco y el de Narciso. A raíz del carácter metafórico de esos dos personajes míticos es posible, por consiguiente, defender el principio de que las figuras de superficie sean eco de la estructura profunda o, entonces, que la relación entre esos dos niveles sea una especie de relación narcísica; un intrincado juego de espejos, de espejos tal vez opacos, inventados por no se sabe quién, para que los seres humanos se enreden en las urdimbres de la significación y sientan, cada uno a su modo, el sobresalto, paradójicamente placentero, de haber caído en las extrañas contingencias de una inmensa trampa.

Quizás todo eso se deba al hecho de que nuestra

idolatrous notion of an objective wordl, independent of our minds, is sustained by the qualitative, subjective feel of our senses, corroborated by objective measure. The raw data of my senses is largely interpreted by me in terms of a construct of reality based on the measurement of physical properties. I do not see a table. What I perceive is an oddly shaped brown area in my visual field. I do not see its height, breadth, and width. I infer these by fitting my touche and visual sensations into a predetermined construct for a table which has certain spatial properties with measurable dimensions. I cannot even feel the thickness of the tabletop or its solidity. I feel only a sensations in my fingers (called pressure) when I try to close them, or an abrupt resistance to my fist swung down before me. These constructs are bolstered by the knowledge that I can measure, and therefore verify, the table $s$

Significação $13 \cdot 92$ 
height, weight, thickness, and so on (JONES, 1982,

p. 14-5).

Pero puede ser también que ese juego especular entre la figuratividad profunda - hondura de lo real de la que procede esa energía irradiadora a la que me he referido hace poco - y la figurativización encuentre una formulación adecuada en la tradición glosemática, en esas ideas de la significación de los no-lenguajes que Fontanille, valiéndose del ejemplo de la música, recupera cuando dice que

il faut se demander résolument si la perception a un sens, et, si elle en a un, d'où elle tient. La question se pose depuis longtemps dans certaines sémiotiques, que Hjelmslev classait parmi les "non-langages"; il en est ainsi de la sémiotique musicale, qui se présente comme une sémiotique monoplane, et dont les seuls signifiés ne peuvent être que connotatifs, soit sur le mode évanescent et insaisissable des effets de sens individuels, soit sur le mode massif et stéréotypé des poncifs musicaux, des scies et des rengaines. C'est dire que si les non-langages signifient, ce ne peut être, une fois mis entre parenthèse les effets connotatifs, qu'à partir de la perception: la signification émerge non pas d'une relation de type classique entre un plan de l'expression et un plan du contenu, mais, pour commencer, au cours du processus qui permet de passer d'une sensation sonore à une perception musicale, puis à une interprétation musicale. En d'autres termes, dans les cas des nonlangages, le parcours génératif de l'expression aboutit à un acte d'énonciation (une interprétation 
musicale, par exemple), et le sens de ce parcours $n$ 'est autre que celui qui se réalise dans cet acte: ce qui est, dans ce cas, modalisé, narrativisé, aspectualisé, spatialisé, etc., c est l'acte même de l'énonciation, et non pas, comme d'ordinaire, des contenus énoncés attachés conventionnellement à des expressions (FONTANILLE, 1995, p. 24).

Al margen de las muchas cuestiones que derivan de la discusión de esas ideas, el interrogante que aquí me interesa se insiere en la concepción que Greimas nos legó al decir que la única presencia concebible de la significación es

\begin{abstract}
su manifestación a través de la "sustancia" que engloba incluso al hombre: lo que llamamos el mundo sensible se convierte así en el objeto, sin exclusión de ninguna parcela, de la búsqueda de la significación: el mundo se revela, en su conjunto y en sus articulaciones más menudas, como una virtualidad de sentido, a condición que sea sometida a una forma por lo menos mínima. Por obra de esta forma, la significación puede introducirse bajo todas las apariencias sensibles. Así, detrás de los sonidos, de las imágenes, de los olores y de los sabores, sin que por ello esté en ellos en cuanto puros soportes informes de nuestra percepción formadora (GREIMAS,
\end{abstract} 1973, p. 49-50).

Definida en esos términos, la significación no puede enterderse sino como algo que debe ser construido, sea cual fuere la dirección que tome esa construcción. Mas, en esta oportunidad, lo que deseo es explorar

Significaçcio $13 \quad 94$ 
algunos aspectos de la capacidad que tiene la metáfora visual de construirle formas poéticas a la significación y, en especial, colocar sobre las cartografías que los lenguajes nos hacen del cuerpo marcas que indiquen posibilidades de qué rumbos tomar para llegar - o al menos vislumbrar vestigios - hasta los bordes de la fantasmagórica carnalidad de un cuerpo primario, de un cuerpo del que no tenemos mapas, pues, en general, la cartografía remite a una corporeidad secundaría y de ella representa accidentes, cordilleras, valles y ríos, porque este cuerpo secundario, conquistado y culturalizado, tiene segnificado, instituye códigos, funciona como un lenguaje, con sus signos, su léxico, su sintaxis, su lógica y su retórica. Pero que, por tras de todo eso, existen, de acuerdo con el pensamiento de Dubois (1988, p. 7-9), indicios del desaparecimiento progresivo de un cuerpo real, de un cuerpo primitivo y primario, de un cuerpo, en fin, del que sólo alcanzaremos algún que otro remanso de sus orillas siguiendo las huellas de los senderos tortuosos que la metáfora traza en las cartografías del soma en que, atemorizada, se refugia la inalienable existencia de cada uno.

Siendo, según los autores de la Rhétorique générale, un fenómeno metasememático, 18 la metáfora, cuando es sensata, para retornara las

18. "D'une part, le néologisme métasémème, que nous adoptons autant par symétrie que parce qu'il désigne mieux la nature des opérations en cause, recouvre en gros ce qu'on appelle traditionnellement les 'tropes', c'est-à-dire notamment la métahore, figure centrale de toute rhétorique" (Groupe $(1,1970$, p. 91). Como se sabe, el semema, en la semiótica greimasiana, resulta de la combinación de una figura sémica - recuérdese que para Hjelmslev la figura es un término que designa partículas expresivas o semánticas que no son signos - con un clasema, o sea, con un sema contextual. Así, por ejemplo, en el caso de Vertumnus, dos espigas de trigo forman las cejas del personaje: tanto las espigas, por el hecho de haber sido cortadas y extendidas, como las cejas tienen semas comunes, en ambos términos se manifiesta la horizontalidad. Pero la combinatoria sememática que estructura la forma del contenido de cada uno de esos lexemas no es la misma. En espiga se actualiza la combinatoria horizontalidad + vegetalidad y en cejas horizontalidad + animal + humano. Al colocar esas dos imágenes - la de las espigas y la de la cejas - en relación metafórica, los semas o clasemas de un semema son sustituidos por semas o clasemas de otro semema. Para los autores de la Rhétorique geńérale, ese proceso de sustitución caracteriza lo metasememático. Esto es, para esos semioticistas, 
palabras de Roland Barthes, encuentra, en el viaje que emprenden sus semas rumbo a la manifestación, lugares de reposo en lexemas previamente construidos. En el caso de la metáfora audaz, el viaje de los semas se hace mucho más largo y misterioso, pues, al final de cuentas, vienen de parajes remotos y nunca se sabe con exactitud cuál es el lugar de su destino. No es lo mismo buscar el término de llegada de una metáfora cuyo punto de partida es una unidad lexemática en la que ocasionalmente toman albergue esos semas viajeros. Por añadidura, los lexemas, en el caso de los lenguajes no verbales, no ofrecen la misma estabilidad habitacional que las palabras de una lengua, unidades siempre claramente delineadas, sin la estructura laberíntica de las problemáticas unidades de un texto pictórico o fotográfico, siempre fabricado con los componentes de diversos sistemas sígnicos.

Desde esa perspectiva, las metáforas arcimbolescas que Roland Barthes considera sensatas son aquéllas en que la analogía construye, para los semas viajantes, pasajes entre la aparente naturalidad de las dos orillas de ese flujo de turbias diferencias por el que navega la significación. Así, como dice el semiólogo francés, Arcimboldo nos convence de que la nariz se parece de una manera natural a una mazorca. ${ }^{19} \mathrm{Al}$ contrario, las

un metasemema es la sustitución parcial de un semema por otro. La metáfora, por consiguiente, es un fenómeno metasememático. Las espigas-cejas del personaje arcimbolesco representan un proceso de humanización de lo vegetal, rasgo caracterizador de buena parte de las metáforas creadas por el artista italiano.

19. No se debe entender que la metáfora sensata sea una figura monosémica. Como cualquier metáfora, ella tiene también una fuerte propensión a la polisemia, a la plurisignificación. Algunas de las metáforas sensatas de Arcimboldo, inseridas en otros contextos, tienen significados muy diversos. Véase, por ejemplo, este pasaje de Thomas DaCosta Kaufman: "Vi sono molti altri aspetti che consentono di rivelare parallelismi nei dipinti. Uno implica un messaggio d'armonia: tutto quanto, frutta, verdura, animali e altri oggetti sono armoniosamente congiunti in ogni testa, e così elementi e stagioni coesistono armoniosamente per constituiré ogni serie. Tale rapporto d'armonia rispecchia il governo armonioso deggli Absburgo" (Kaufman, 1987, p. 100). A este respecto, no puedo dejar de citar aquí el siguiente trozo de "Le passioni del volto": "È la posterità di Arcimboldo: la liberazione degli oggeti consente la proliferazione immanente della combinatoria plastica, della resa sensibile. L'emozione si darà allora come iscrizione topologica,

Significação $13 \cdot 96$ 
otras metáforas arámbolescas, las audaces, son, según Barthes, fruto de la desenvoltura, resultado, diría yo, de un proceso que, en la teoría freudiana, sería clasificado como ominoso: cambiar las cosas de lugar, ponerle, por ejemplo, a Herodes, las nalgas de un niño en el lugar de las orejas. ${ }^{20}$ Tal desequibrio produce algo extravagante, una violación, como la que hace Magritte, usando el procedimeinto arcimbolesco en la composición que lleva, precisamente, el título de $L e$ vio/. Esos dos mecanismos metafóricos, esas dos maneras de organizar la significación

volumétrica, cromatica, non come lettura fissa, patognomica del mondo e degli uomini. L'emozione si muta in sensazione e viceversa nella autonomia delia pratica artística. Passione profonda che precede ogni investimento figurativo, polimorfa e multisensibile, iscritta nelle sostanze e nelle forme, nei processi e nei ritmi” (FАвВR, 1987, p. 271-2).

20. Es sabido que la metáfora se fundamenta en un juego de identidades semánticas y, en ese sentido, el factor de la repetición de lo igual juega en ella importante papel. Desde tal punto de vista, puede decirse, por consiguiente, que la metáfora posee una índole ominosa, principalmente si, conforme a lo que nos dice Freud, admitimos que "la repetición de lo igual como fuente del sentimiento ominoso acaso no sea aceptado por todas las personas. Según mis observaciones, bajo ciertas condiciones y en combinación con determinadas circunstancias se produce inequívocamente un sentimiento de esa índole, que, además, recuerda al desvalimiento de muchos estados oníricos. Cierta vez en una calurosa tarde yo deambulaba por las calles vacías, para mí desconocidas, de una pequeña ciudad italiana, fui a dar en un sector acerca de cuyo carácter no pude dudar mucho tiempo. Sólo se veían mujeres pintarrajeadas que se asomaban por las ventanas de las casitas, y me apresuré a dejar la estrecha callejuela doblando en la primera esquina. Pero tras vagar sin rumbo durante un rato, de pronto me encontré de nuevo en la misma calle donde ya empezaba a llamar la atención, y mi apurado alejamiento sólo tuvo por consecuencia que fuera a parar ahí por tercera vez tras un nuevo rodeo. Entonces se apoderó de mí un sentimiento que sólo puedo calificar de ominoso [...]" (FREUD, 1992, p. 236-7). En un texto artístico, la metáfora tiene algo de esas mujeres pintarrajeadas: inquieta $y$ atrae, pues, por las ventanas de sus casitas semánticas, se asoman significados que perturban el, casi siempre moralista, sentido común que se adapta comodamente al trazado aparentemente protector de las callejuelas que circundan lo poético. La metáfora asombra y, cuando menos el lector espera, le atraviesa las entrañas, dejándole en los surcos abiertos por su traviesa travesía la simiente de lo ominoso. La metáfora es una especie de machacona de la identidad: la repite con insistencia hasta destruir las diferencias, ya que la "métaphore extrapole, elle se base sur une identité réelle manifestée para l'intersection de deux termes pour affirmer l'identité des termes entiers. Elle étend à la réunion des deux termes une propriété qui n 'appartient qu'á leur intersection" (Groüpk p., 1970, p. 107). En esa propiedad reside precisamente su índole ominosa, la impresionante capacidad de libertar la realidad que el sentido común, siempre testarudo, 
determinan, en fin, el interrogante al que deseo dedicarme, en esta oportunidad, con más ahínco.

Las metáforas sensatas se encajan perfectamente en los modelos formulados por los autores de la Rhétorique générale. Así, si en L 'Autunno, la copa de un cogumelo se transforma en una oreja, la metáfora que ahí se forma es, sin duda, una metáfora por suma lógica, resultado de la combinación de dos sinécdoques: una generalizante y la otra partja> larizante. La metáfora constituida por la imagen de las nalgas como equivalente de orejas se hace, si seguimos rigurosamente la fórmula del Groupe p, más problemática. Sería, en principio, una metáfora por producto lógico ${ }^{21}$ como parece que lo son las metáforas del cuadro de Magritte Le viol. Hay en este tropo un juego de permutaciones y la permutación, como dicen los autores del Traité du signe visuel, es

une figure rare, sans doute en raison de l'effet violent et quasi tératologique qu elle produit. // $n$ est donc pas étonnant d'en trouver l'exemple le plus net chez un peintre surréaliste comme Magritte: dans Le viol (1934), le visage féminin représenté (et identifiable comme tel grâce à la chevelure et à sa position sur un cou) voit ses yeux figurés par deux seins. [...] Dans ces figures, "paire d'yeux" ou "paire de seins"

se empeña en ocultar. Esa invasión arrolladora de los territorios del hábito que la metáfora efectúa con el auxilio de los rasgos semánticos de un vislumbre de realidad no reprimida forma la comba de que necesita lo ominoso para saltar.

21. Para los autores de la Rhétorique générale, la descomposición por producto lógico ocurre cuando, por ejemplo, dividimos un árbol en partes - ramas y hojas y'tronco y raíces -: "Les parties sont entre elles dans un rapport de produit logique II (conjonction et) et nous désignerons l'ensemble par décompasition sur le mode II" (Groupe $\mid \mathrm{X}, 1970$, p. 100). Así, si tomamos la metáfora que nos dan como ejemplo - bateau usado en lugar de veuve -, el punto intermediario sería voiles, elemento que, colocado en relación con bateau, constituye una sinécdoque particularizante por producto lógico, sucediendo que veuve, puesta en relación con voile instaura una sinécdoque generalizante. La metáfora por 


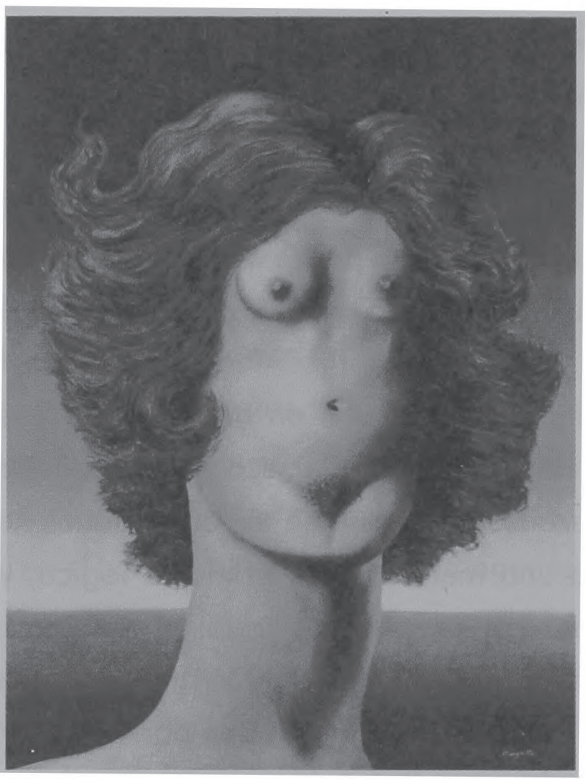

peuvent s'intervertir. Chaque organe est parfaitement reconnaissable, et le reste du corps également: le seul écart réside dans l'emplacement des parties, qui trouble à la fois la coordination et la subordination. [...] Et la base de ces métaphores est comme toujours la copossession de quelques traits, par exemple ceuxci: "vont par paires", "apparaissent comme demisphères", "possèdent un point sombre centrale" $A$ ces traits $s$ en ajoutent d'autres comme "objet d'attirance", "mous et pleine de liquide", ces trait typologiques $n$ étant pas visuels, mais figurant dans la compétence encyclopédique des usagers (Groupe I/, 1992, p. 303).

producto lógico se estructura, pues, según la fórmula siguiente: $(\mathrm{Sp}+\mathrm{Sg}) \mathrm{II}$. O sea, las velas de una goleta permiten - en francés la palabra voile significa vela y velo - establecer una relación con viuda, ya que la vela, en cuanto lienzo, es una parte de la goleta y de la viuda. 
Por lo que se dice en el pasaje transcrito, la metáfora en cuestión, si la enfocamos desde un punto de vista estrictamente visual, es una metáfora por producto lógico. En otras palabras, el término intermediario de la metáfora senos-ojos podría ser la combinatoria pezón-córnea,22 pues estos dos vocablos, en cuanto partes de los órganos corporales puestos en relación, poseen algo en común. La córnea tiene la forma de disco abombado y el pezón es el vértice de la mama, de forma de botón. Ambas conformaciones se sitúan en el exterior de los órganos a que pertenecen. El subconjunto de intersección que se instaura mediante la combinatoria pezones-córneas crea las condiciones necesarias para la identificación de una metáfora por producto lógico, ya que, como se puede comprobar con relativa facilidad, el término intermediario así definido instituye, en su relación con el término de partida - los pezones son parte de los senos -, una sinécdoque particularizante y, a su vez, el término de llegada, vinculado al punto intermediario, establece una sinécdoque generalizante por el hecho de que los ojos incluyen las córneas.

Claro que si consideramos el sema de la "redondez", podremos leer esa metáfora según el molde de una descomposición por suma lógica, ${ }^{23}$

22. Podría establecerse una correlación más precisa todavía si relacionásemos pezón-aréolamama con córnea-pupila-ojo.

23. "Nous pouvons également considérer notre arbre - recuérdese que para explicar la descomposición por producto lógico, los autores utilizaron el vocablo árbol, como se señaló en la nota 20 de este trabajo - comme une classe constitué d'individus équivalents sous le rapport choisi: la classe des arbres est constitué par les peupliers et les chênes et les bouleaux, etc., mais un arbre particulier, individu quelconque de la classe Arbre sera

arbre $\mathbf{x}=$ peuplier $o u$ chêne $o u$ saule $o u$ bouleau...

Ces éléments sont à la classe dans une relation d'espèce à genre; ils sont donc mutuellement exclusifs. Les disjonctions par lesquelles on crée les espèces au sein du genre, placent celles-ci dans les rapports mutuels de somme logique. Les genres sont décomposés en espèces grâce à des attributs 'distinctifs', c 'est-à-dire grâce à des sèmes nouveaux non pertinents dans la définition du genre. La décomposition $n$ est pas distributive, mais attributive, chaque partie étant un arbre et possédant tous les sèmes de l'arbre plus des déterminants particuliers. Les parties sont dans un rapport de somme logique $\mathrm{S}$ (conjonction ou) et nous désignerons cet ensemble par décomposition sur le mode X" (Groupe $\mid \mathbf{i}, 1970$, p. 100).

Significaçôo 13100 
esto es, en base a un modelo en que el término intermediario constituido por la "redondez" permite, cuando lo relacionamos con el término de partida - senos -, formar una sinécdoque generalizante y el término de llegada - ojos - asume, si lo ponemos en relación con "redondez", la función de una sinécdoque particularizante.

Cada una de esas construcciones determina especies diferentes de metáforas. Unas - las formadas por producto lógico - determinan una práctica de lectura centrada fundamentalmente en la visualidad, o sea, en imágenes que percibimos a través del sentido de la vista. Otras - las formadas por suma lógica - determinan, al contrario, una práctica de lectura arraigada en el humus de las llamadas imágenes mentales, o sea, de imágenes que pertenecen al intelecto o a la memoria. Las primeras, como ya fue observado por los autores de laRhétorique générale (1970, p. 100), propenden, al privilegiarei hecho de ponerla mirada en dirección de una de las partes de un todo, a lo exocéntrico. Eso es precisamente lo que sucede con la metáfora goleta-viuda, pues, sin duda, a su creador se le ocurrió la idea de armar la relación entre los dos términos a partir de una de las partes que ambos tienen en común: vela/velo. Las segundas propenden, a su vez, a lo endocéntrico: el atributo de la "redondez" subyuga, en sus dominios semánticos, un número enorme de términos. A la "redondez" pertenecen, por ejemplo, las colinas, los senos, los ojos, la pelota, la manzana y, para no citar más, la cebolla. De modo que, a medida que se trabaja con modos diferentes de descomposición, el término intermediario de la metáfora cambia y, en razón de ello, el tropo, al actualizarse a través de diferentes estructuraciones semánticas, desencadena tensiones en un campo de significación que oscila entre lo genérico y lo particularizado, esto es, entre una inclinación de la carga significativa hada el todo o hacia las partes.

Tal constatación puede resultar relevante para el estudio de ciertas características del género retratístico, género en que las relaciones cuerpomundo e individuo-mundividencia asumen un papel fundamental, como los rápidos comentarios a retratos clásicos de la pintura occidental aquí 
esbozados ya dejan entrever. En el caso de El bibliotecario, Arcimboldo propasa el paradigma clásico que se delinea en las propuestas pictóricas de Zeuxis ${ }^{24}$ al hacer que, en las hojas de un libro abierto, el espectador del cuadro vea la melena de un hombre. ${ }^{25}$ Los bordes afilados de unas

24. En sus Imagines, Filóstrato comenta sabrosamente una especie de bodegón diciendo: "Oscuros higos chorreando jugo y amontonados sobre hojas de parra aparecen pintados con grietas en su superficie, algunos justo en el momento de abrirse para descargar su miel, otros partidos ya de tan maduros. Junto a ellos hay una rama, y por Zeus que no está pelada ni carente de fruto, pues a su sombra pueden verse más higos, unos aún verdes e inmaduros, otros arrugados y pasados de sazón, otros entreabiertos y destilando lo mejor de su zumo; y en lo alto de la rama un gorrión hunde el pico en el higo que parece más dulce" (Fh.óstrato El VIejo, 1993, p. 90). Esta descripción de lo que hoy llamaríamos una naturaleza muerta y que los griegos denominaban xenia (ofrendas de hospitalidad), nos coloca en la pista de lo que sería la propuesta pictórica de Zeuxis tal cual fue, en parte, relatada por Plinio en su Historia natural al contarnos que Parrasio y Zeuxis tuvieron, un día, una disputa sobre el realismo de sus respectivas obras. Zeuxis exhibía, con incontenido orgullo, la pintura de unas uvas tan realistas que los pájaros se aproximaban al lienzo con la intención de picotearlas. Pero Parrasio, ni corto ni perezoso, expuso ante los ojos de su rival el cuadro de una cortina tan realista que Zeuxis, considerándose vencedor por el veredicto de los pájaros, creyó que su contrincante tendría que correr la cortina y empezar a pintar su obra. Mas al descubrir que se había engañado, tuvo que reconocer su derrota, pues si él había engañado a los pájaros, Parrasio fue mucho más lejos al coseguir engañarlo a él mismo. Norman Bryson, en el ensayo precisamente titulado Xenia, comenta el legendario episodio relatado por Plinio de la siguiente manera: "The story has been cited so often in the annals of art history, as a parable of realism, that it is easy to miss its most remarkable feature, the strangeness of the episode's location. One can begin to indicate this strangeness by dividing the story into two halves, around its two pictures. The 'still life' of the grapes brings birds out of the sky: perhaps one thinks of the birds as flying up againts the painted surface and, so to speak, hitting a pane of glass. Yet the wording of the text has another emphasis: the painted grapes were so successful ('uvas pictas tanto successu') that the birds flew 'up to the walls of the stage' ('ut in scaenam aves advolarent'). Zeuxis picture is in fact an instance of what the Greeks termed skenography, painting for the theatre" (BRYSON, 1990, p. 30-1). De modo que la naturaleza muerta, vista como un género pictórico en que se encuadra perfectamente la propuesta de Zeuxis, mantiene con el género retratístico una estrecha relación, una relación que si, por un lado, sirve para preservar la tradición, por otro, se ofrece como algo fuertemente codificado que propiciará - eso se verá más adelante- la formación de un espacio semiótico cuya solidez constituye un factor favorable a la irrupción de las rupturas poético-metafóricas.

25. Al comentar el lienzo Vertumnus, Schneider observa precisamente eso cuando afirma que "Arcimboldo, whose art, according to Comanini, outdoes even that of antique

Significado $13 \quad 102$ 
hojas de papel simulan unos hilos de pelo y, en ese juego de analogías, los filos y los cabellos conjuntan partes comunes para construir una figura, en el sentido retórico del vocablo, cuya principal característica parece residir en el hecho de que el cuerpo conquistó la capacidad de acoger, en los diversos y diferentes territorios de su anatomía, las cosas que no le pertenecen. Si es verdad que los bordes afilados de las páginas de un libro forman, cuando los relacionamos con los cabellos, una metáfora por producto lógico, también es verdad que los términos de esa metáfora, vistos desde el ángulos de los semas atributivos, actualizan, al mismo tièmpo, una metáfora por suma lógica.

Ese vaivén entre lo endocéntrico y lo exocéntrico, sin embargo, debe ser pensado en términos de una tensión dialéctica, ya que las metáforas arcimbolescas por producto lógico ocasionan rupturas en el sistema de relaciones del cuerpo con los elementos del mundo físico o de las circunstancias configuradas por los objetos artificiales. En los retratos renacentistas, las cosas que rodean la coporeidad, como ya se ha observado, mantienen con el cuerpo una relación complementaria. Mas, en el caso de Arcimboldo, esas mismas cosas o elementos de la naturaleza, se desplazan desde sus sitios para ocupar un lugar preciso en las cartografías somáticas armadas por el pintor. Puede decirse, por consiguiente, que en esos retratos mágicos y caprichosos, el mundo se hoce cuerpo. $\mathrm{Y}$ todo eso porque en ese tipo de metáforas "le seul écart réside dans I 'emplacement des parties"

A todo eso hay que añadir que la imagen de los ojos y la imagen de los senos no son, si consideramos la heterogeneidad semiótica del texto visual en que ocurren, exactamente unidades lexemáticas. Los propios autores del Traité du signe visuel, lidian - dígase, por cierto, que de

painter Zeuxis, creates the illusion that we are looking at parts of the body when he is realy showing us spiked ears of June corn, summer fruits etc. In this sense, the apparent chaos of the composition forms a unity, just as Rudolf II comprises many different things in one person" (SCHENEIDHR, 1994, p. 123). 
manera muy eficaz - con tres sistemas semióticos básicos: el de la forma, el de la textura y el del color. Evidentemente que cada uno de esos sistemas engendra sus unidades sígnicas específicas y, como parece claro, la imagen de los senos, que puede ser vista como el término de partida de la metáfora, es una imbricación de varios signos, fenómeno que determina una cierta inestabilidad en las formas expresivas de los textos visuales, ${ }^{26}$ hecho que, en el fondo, dificulta el intercambio que presupone la idea de que "paire d'yeux" y "paire de seins" peuvent s'intervertir. Consecuentemente, el plano de la expresión en que se manifiesta este tipo de metáfora adquiere las propiedades de un soporte expresivo cuya principal característica radica en su heterogeneidad semiótica. En tanto resultante de una combinatoria en que se imbrican diferentes unidades sígnicas, la semiosis que ahí instaura sus relaciones de presuposición multiplica la significación de la misma forma que los espejos de un calidoscopio multiplican las imágenes. El contenido que se manifiesta en una de las extensiones significantes puede también "mirarse", por decirlo así, en la superficie especular de otra de las extensiones o "escuchar" el sonido lejano que se refleja, amortiguado, en cualquier extensión significante de ese calidoscopio expresivo. Tal vez la singularidad que en semejante proceso asume la significancia sea un buen motivo para pensar en el papel que el doble juego, el de Narciso y el de Eco, desenpeña en ese hervidero de significaciones en que se forja la metáfora visual.

A causa de ello, las metáforas de los senos/ojos y de las nalgas/

26. Obervése, para elucidar aspectos de esta cuestión, que la percepción, por parte del espectador de un cuadro, está sujeta, con a reglo a la distancia entre el observador y la obra observada, a oscilaciones. Por ejemplo, en el caso del sistema de la textura, un elemento de textura "se caractérise par une dimension réduite, dimension telle qu on ne puisse pas en faire une forme, car la peception individuelle de ces éléments cesse à partir d'une certaine distance, et est remplacée par une appréhension globale grâce à une opération d'intégration. Ceci implique une distance type entre le spectacle et le spectateur. ${ }^{17}$ La texture du plafond de Sant'Iganizio, vue à trente mètres, sera déterminée par des éléments bien plus grands que ceux d'un timbre-poste examiné à la loupe" (Groupe h, 1992, p. 197-8).

Significaçôo $13 \quad 104$ 
orejas no sólo favorecen el hecho de que "l'écart réside dans l'emplacement des parties", sino también la constitución de un plano expresivo propicio a los fenómenos de condensación, lo que confiere a sus calidoscópicas formas significantes una índole onírica. ${ }^{27}$ Conviene agregar a lo dicho que, considerando los cuatro modos metafóricos establecidos por los autores del Traité du signe visuel, ${ }^{28}$ cada una de tales modalidades metafóricas matiza las relaciones estructurales de los dos términos que integran la figura retórica propiamente dicha. Si en ellas revelamos extravagancias, audacias u ominosidades es porque los términos puestos en conexión pasan por entre los invisibles vacíos de una urdimbre hecha con las hebras de la presencia o de la ausencia de las cosas relacionadas, con las tensiones de las cosas que se unen o se separan. Cuando Barthes dice que la metáfora de los dientes es una tautología apunta, con las armas de su habitual argucia, a uno de los matices más característicos del tropo arcimbolesco.

A primera vista, los dientes del escualo se confunden con los del personaje retratado. Eso significa colocar al espectador del cuadro frente a una metáfora en que los dos términos que la integran estarían presentes y, además, mantendrían entre sí una relación de conjunción. O sea, esa figura tiene todas las características de una metáfora in praesentia

27. En más de una oportunidad he estudiado este aspecto y en mi trabajo "La metáfora visual" (1992, p. 69-86) trato de defender la hipótesis de que la auténtica metáfora visual se diferencia de la literaria porque el significante en que se manifiesta asume todas las características de una condensación.

28. EI Groupe |I, al estudiar las cuestiones paradigmáticas de la retórica icónica, establece cuatro modos metafóricos: 1) in absentia conjunta (IAC), que se da cuando en los ojos de un borracho pintamos, en lugar de las pupilas, dos botellitas; 2) in praesentia conjunta (IPC), que ocurre, según el ejemplo de los autores, cuando una cafetera semeja un gato; 3) in praesentia disyunta (IPD), que puede ser ilustrada por la tela de Magritte titulada Les Promenades d'Euclide, cuadro en el que aparecen dos conos sombreados - uno corresponde al tejado de una torre puntiaguda y el otro a la perspectiva de una avenida; y 4) in absentia disyunta (IAD), como ocurre cuando las corvas de varios cuerpos femeninos imitan las ondulaciones de una cadena de montañas (Groupe $\mid$, 1992, p. 273-8). Cf. SONESSON (1997, p. 49-76). 
conjunta. Pero si detenemos la mirada en esa configuración, nos convencemos, con relativa facilidad, de que los dientes del escualo no son los dientes del personaje. Nos convencemos, por consiguiente, de que los dientes del personaje están ausentes, no hacen parte de la extensión significante en que la metáfora se manifiesta. Sin embargo, la sensación de su presencia persiste, pues, a pesar de la veracidad de la ilusión, el espectador continúa viendo los dientes del personaje. En otras palabras, la oscilación entre la percepción de una metáfora in praesentia conjunta y de otra in absentia disyunta produce un sentimiento ominoso, un sentimiento que insinúa la posibilidad de existencia de un tipo de metáfora en que las dos modalidades cohabitan en las entrañas de una misma extensión significante.

En ese contexto, la metáfora que me parece más insinuante es la que se presenta bajo la modalidad de un a absentia disyunta en que se camufla una praesentia conjunta. Ésta, en verdad, es una figura en que la ominosidad es uno de sus rasgos más definidores y, aunque sus raíces se encuentran en la metáfora arcimbolesca, ${ }^{29}$ sea más o menos sensata o más o menos audaz, alcanza su plenitud en el Surrealismo. En la obra de Magrítte aparece con inusitada frecuencia y, en algunos cuadros - La philosophie dans le boudoir, Le soirqui tombe, La condition humaine... las imágenes adquieren un cariz inquietante en el que se ponen al abrigo figuras poéticas cuya opacidad semántica contribuye para crear un clima de misterio. David Sylvester achaca a la muerte de la madre del artista el entrañable origen de los rasgos ocultos de gran parte de su obra:

\section{Whatever its formation, Magritte $s$ fantasy about his} mother's death has many echoes in his paintings.

There are severa/ which evo/ce death by water; thére

29. Acerca de esta cuestión, la lectura de la "Antología di testi del XX secolo", trabajo en que Piero Falchetta reúne una serie de textos de artistas y críticos del siglo $\mathrm{XX}$ dedicados a Arcimboldo, es recomendable (FALCHETAA, 1987, p. 207-34).

Significação 13 * 106 
are numerous instances of faces which are somehow concealed or absent. Examples began to appear as soon as he rejected the formalism ofhis earlywork and turned in 1925 to using painting as a means to the realization ofapoetic image (SYLVESTER, 1992, p. 14).

Sin querer esquivar en nada la importancia de esas ideas, lo que me interesa en tales particularidades expresivas es subrayar los indicios de una de las actitudes más significativas de la imagen surrealista. Me refiero específicamente a ese procedimiento de ocultación del rostro o al hecho de trasladar los órganos corporales de un sitio para otro, arrancarlos de sus lugares propios para incrustarlos violentamente en inesperados puestos de la corporeidad. Ya se ha visto que, en Le viol, Magritte muestra un rostro y al mismo tiempo nos oculta otro, desplaza órganos de modo a transformar el ombligo en esperpento de nariz y la vulva en boca.

En ese proceso, como en los sueños, el cuerpo se hace mundo y, consecuentemente, medida de todas las referencias. Por eso, la cartografía que lo representa fija, en las configuraciones ¡cónicas de sus mapas, ${ }^{30}$ índices y señuelos que atraen nuestra curiosidad, que nos fascinan y, a veces, nos provocan una extraña inquietud. ${ }^{31}$ En general, el fascinio que nos causa ese tipo de cartografía radica en el erotismo de que se impregnan sus accidentes corpográficos y la sinuosidad de sus relieves. Porque, en el fondo, todas esas configuraciones en que se realiza el tipo de metáfora de que estoy hablando tienen una fuerte conexión con lo simbólico y, especialmente, con isotopías sexuales, ya que en esas

30. No se puede negar que la extensión significante que traza los rasgos del rostro arcimbolesco observable en el cuadro de Magritte reproduce, analógicamente, la forma de la faz, o sea, instaura un signo icònico.

31. Para sentir el alcance de esta inquietud, recomiendo, como impresdincible, la lectura de "Beyond the pleasure principie?", primer capítulo del libro Convulsive beauty (FosTER, 1997, p. 1-17).

Significação $13 \cdot 107$ 
figures, les types identifiés à première lecture donnent un sens satisfaisant à l'énoncé, mais nous avosn tendence à réinterpréter ce sens à la lumière des isotopies projetées.

Ces isotopies sont bien souvent sexuelles, une obsession libidineuse étant à la base de notre esprit perpétuellement mal tourné. L'image visuelle ne leur échappe pas, où abondent les allusions phalliques ou vaginales (Groupe sıx, 1992, p. 275).

Además, en Le viol, los índices tienen un fuerte parentesco con lo fotográfico. Poco importa si el tema de este cuadro, como ya fue observado, ${ }^{32}$ no es nuevo. Lo relevante, en este caso, reside en la estructura de la configuración poética de un mapa facial hecho con signos indicíales e imágenes iconográficas. Para algunos, la fotografía se define como una emanación del referente ${ }^{33}$ y esa es la definición de que se sirve Philippe Dubois para valorar los aspectos indicíales del acto fotográfico:

32. "Rigour and economy of realization are what make The rape spellbinding, for its basic idea is nothing new - that a frontal female torso suggests a face, an idea exploited by the Surrealists, an idea which (as Patrick Hughes pointed out to me) was melodramatized one summer evening in 1816 at the Villa Diodati on Lake Leman. The Shelleys were there talking of ghost stories with Byron... [...] The rape partakes of that sense of horror, while at the same time being hilarious. Every detail is incisively meaningful. Isolated at its centre is a navel which is a nose eaten away by tertiary syphilis. The pubic hair acts like the fur adorning Meret Oppenheim s cup, saucer and spoom. And, if this takes us as we look into reveries of cunnilingus, it becomes embarrasing suddenly to realize that this delicious pubic beard is also a comical little beard on a man's face. The head-hair, on the other hand, is not at all comical but shaped so that it is horrfyirig in a way which brings Shelley's hallucination to mind |...J" (SYLVESTER, 1992, p. 230-1).

33. Cuando me refiero al parentesco de la pintura de Magritte con la fotografía, no quiero decir, es obvio, que la pintura sea una emanación del referente. Lo que quiero decir es que el pintor belga parace haber asumido el compromiso de crear conformaciones pictóricas que simulan un efecto de referente.

Significaçâo $13 \cdot 108$ 
Pour l'instant, je soulignerait simplement ceci: c "est que la photographie, avant toute autre considération représentative, avant même d'être une "image" reproduisant les apparences d'un objet, d'une personne ou d'un spectacle, est $d$ abord, essentiellement, de l'ordre de l'empreinte, de la trace, de la marque et du dépôt (marque déposée, dirait Denis Roche). En ce sens, la photographie appartient à toute une catégorie de "signes" (sensu lato) que le philosophe et sémioticien Charles Sanders Peirce appelait "index", par opposition à "icône" et à "symbole"(DuBols, 1988 , p. 59).

El texto fotográfico termina siendo, por consiguiente, el resultado de la combinación de una intrincada pluralidad de sistemas semióticos que evidencia la primacía de los signos indicíales e ¡cónicos.

En el caso específico de la fotografía erótico-fetichista, los índices y los signos ¡cónicos establecen sugestivas relaciones comparativas, como se constata en esta foto de Christian Vogt.

Aquí la armonía de líneas del cuerpo femenino rima con el equilibrio geométrico del objeto. La proporción y la correspondencia de las cosas comparadas erigen, en principio, un símil caracterizado por la presencia de los dos términos cotejados. Pero

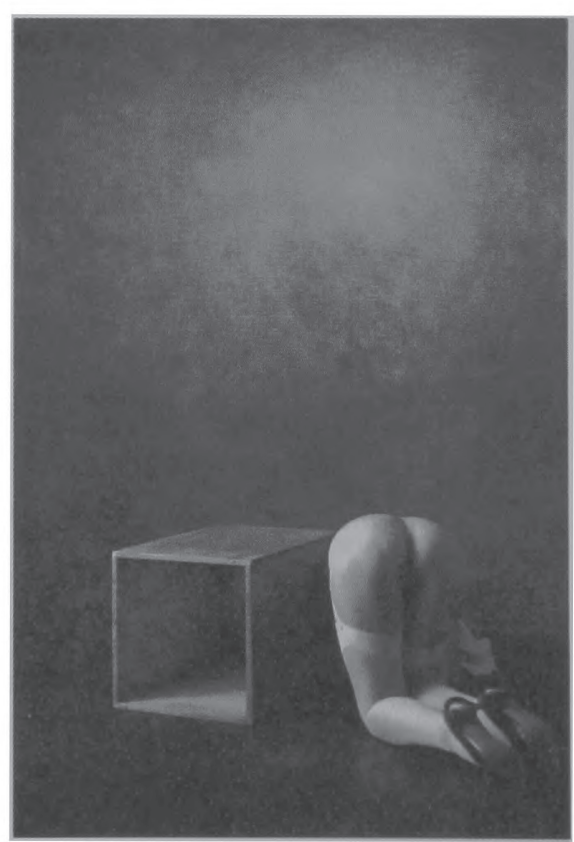

Significação 13 109 
la exposición velada de las partes íntimas de la mujer comparada con el boquete del cajón sin tapadera forman, de modo subrepticio, una metáfora cuya praesentia disyunta de los dos componentes se ofrece a la percepción visual tenuamente. La hendidura entre las nalgas que, sin rodeos, conduce la vista hasta ese obscuro borrón en el que el espectador presiente el blando terciopelo de la vulva encuentra, casi que de repente, la ilusoria explicación del imaginado misterio de su interioridad en el vértice, también obscuro, sobredeterminado por los dos triángulos que esbozan ranuras en la geometría interior del cubo.

En la articulación de esas dos figuras, el símil es el umbral de una metáfora cuyos sentidos remiten, creo, a las imprecisiones de un referente invisible en el que se apoya la imaginación de los hombres para armar devaneos y sublimar sensaciones. Todo eso porque, en el fondo, los resquicios de la referencialidad somática que se enredan en la polisemia de ese tipo de metáfora tienen origen, a lo que parece, en nociones que, desde el Renacimiento, arraigan en saberes acerca del cuerpo. Uno de los que se injerta perfectamente a la espinosa semiosis del tropo en cuestión es, sin duda, el que retoñó con la ¡dea de que las representaciones del cuerpo constituyen una construcción simbólica, pues, como señala Le Bretón, el cuerpo
parece algo evidente, pero nada es, finalmente, más
inaprehensible que él. Nunca es un dato indiscutible, sino el efecto de una construcción social y cultural.
La concepción que se admite con mayor frecuencia en las sociedades occidentales encuentra su formulación en la anatomofisiología, es decir, en el saber que proviene de la biología y de la medicina.
Está basado en una concepción particular de la persona, la misma que le permite decir al sujeto "mi cuerpo", utilizando como modelo el de la posesión (LE BRETón, 1995, p. 14).

Significagáo $13 \quad 110$ 
A los surrealistas les interesa esa inaprehensibilidad. ${ }^{34}$ No sólo porque tal concepción presupone la existencia de imágenes del cuerpo que se ocultan, sino porque semejante proposición se presenta como un desafío, un reto que desencadena un conjunto de tentativas poéticas integradas todas en el propósito de conseguir formas expresivas capaces de enriquecer la construcción simbólica de lo corporal y, al mismo tiempo, plasmar entidades artísticas a partir de las cuales el ser humano se acerca un poco más a sus fantasmas, a la realidad espectral en que se disuelven las falsas concretudes de lo cotidiano. Entre otras cosas, eso es lo que nos muestra Le viol, ya que, en sus metáforas, se exhibe, con cierto alerde irónico, el desencanto provocado por la rigidez de los modelos anatomofisiologistas. Preñadas de ominosidad, las formas expresivas más típicas del Surrealismo revelan un incontenible deseo de buscar modelos que conviertan la representación del cuerpo en la cartografía de un sueño ancestral. Ese vaivén tenso entre los signos indicíales e ¡cónicos que se alberga en las metáforas del cuadro de Magritte tiene raíces en las honduras de la idea de que el inconsciente es un lenguaje,

mais un langage qui a oublié tous ses mots et ses

signifiants de chose, et qui tente presque en vain de

34. La preocupación por lo informe puede ser uno de los indicadores de tal actitud. Rosalind Krauss afirma que los fotógrafos surrealistas "furent les maîtres de l'informe obtenu, comme Man Ray $s^{-}$en était rendu compte, par simple rotation et par là même, désorientation du corps. C'est ce que fit Boiffard pour son nu tragique publié dans le magazine de Bataille Documents (fig. 54), ou Brassai dans l'extraordinaire image choisie pour 'Variétés du corps humain', essai publié en 1933 dans le premier numéro de Minotauré (fig. 48). Brassai utilise la même stratégie que dans Anatomies: le regard de la caméra remonte en contre-plongée le long de la forme étendue afin de capter, de fabriquer (ou est-ce d'imaginer?) le corps nu révélé en tant qu animal. Car la lumière, qui plonge les hanches et les cuisses dans une obscurité.faite d'ombres, de même que l'angle de vue qui fait disparaître la tête derrière le haut du torse et les épaules, se conjuguent pour donner l'image d'un animal inconnu: les seins protubérants suggèrent les touffes cornées du front, le torse et le bras lumineux tiennent lieu de visage et d'oreille" (Krauss, 1985, p. 60). 


\begin{abstract}
les reconstituer. C'est-à-dire que la pulsion, exprimant un besoin et un désir, est toujours inconsciente mais cherche sans cesse sa satisfaction. C'est l'estimulant incessant qui mène à la production des processus secondaires, comme les appelle Freud, c est-à-dire ceux qui construissent les oeuvres de culture: le langage, la pensée, les arts, les sciences, les techniques, etc. La pulsion ne trouve les meilleurs chemins de la satisfaction, à travers les processus de sublimation, qu en se liant à des nouveaux représentants de chose ou de mot, différents mais analogues, sous certains aspects, aux représentants primitifs refoulés (Saint-Martin, 1997, p. 16).
\end{abstract}

En el lienzo de Magritte, la geografía del rostro se transforma. La individualidad captada en la tradición del género retratístico sufre cambios radicales. Las referencias a lo circunstancial se diluyen, ${ }^{35}$ no hay necesidad de un gesto de manos para hablar del matrimonio de dos personajes y el mundo establece sus fronteras en el mundo del cuerpo. Por todo eso, el retrato del pintor belga coloca al espectador ante una imagen que funciona como representante de cosa $\mathrm{y}$, consecuentemente, como representante de una corporeidad reprimida. Pero visto desde una perspectiva retórica, ese representante de cosa, en tanto extensión significante, transmuta la estructura habitual de la metáfora. Los índices, casi fotográficos, dialogan pictóricamente con la finalidad de aproximar los elementos distantes piénsese en la metáfora de los pezones/ojos -, sin eliminar, empero, su

35. El proceso de disolución del referente concreto, en cuanto mecanismo indispensable para la creación de formas significantes que hagan la vez de representantes de cosa, tiene una estrecha ligazón con el principio surrealista centrado en la idea de eliminar del signo su sujeción a la cosa representada. Breton lo define de varias maneras en sus Manifiestos y, principalmente, en Lí Surréalisme et la Peinture (1965).

Significaçâo $13 \quad 112$ 
conexión con una referencialidad concreta, mientras que los signos ¡cónicos, manipulados por las fuerzas del simbolismo, pueden transcender esa referencialid para remitir a una iconografía arcimbolesca. Sin embargo, la mediación entre unos signos y otros, o sea, la construcción retórica de un campo de intersección entre bs términos de la metáfora es matizada por el encuadre y el ángulo de visión. Esos dos factores sobredeterminan cargas simbólicas y, en muchos casos, son directamente responsables por los efectos de ominosidad.

En base a todo lo expuesto, creo que el representante de cosa, tal como se presenta en las imágenes más genuinamente surrealistas, tiene la traza, en primera instancia, de lo que yo llamaría una metáfora iconográfica. En otras palabras, de una metáfora en que el término de partida es una iconografía indicial y el término de llegada una intrincada configuración iconográfica. Todo eso ordenado a través de formas expresivas en las que el encuadre y el ángulo de visión ejercen fuerte interferencia simbólica. Le vio/ pone eso en evidencia al armar una construcción simbólica del cuerpo en que la vulva, sitio de apetitos no alimentares, ocupa el lugar de la boca. A nivel meramente perceptivo, esa metáfora tiene sus fundamentos más sólidos en la iconografía determinada por los signos indicíales. Mas, en segunda instancia, el retrato ominoso que Magritte consigue usando el recurso de desplazar los índices, es, a su vez, término de partida para una metáfora que define su término de llegada a través de una configuración iconográfica que reproduce un retrato a la manera arcimbolesca.

Una metáfora que, según el siguiente esquema,

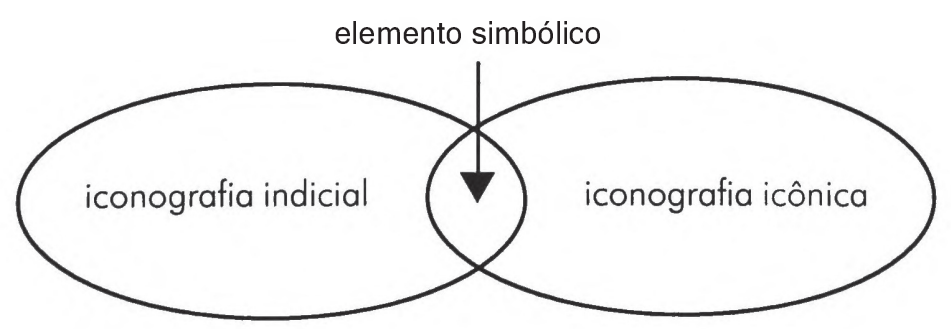

Significação $13 \cdot 113$ 
los índices funcionan como términos de partida, el encuadre/ángulo de visión como elemento intermediario y las iconografías como imágenes que sugieren el retrato "íntimo de una mujer"

Creo, pues, que la extensión significante así construida engendra un representante de cosa en el que bajo la modalidad de una ausencia disyunta se camufla una presencia conjunta. Tal representante de cosa insinúa, si mi intuición no se engaña, la existencia de referentes que no hacen parte de esa reducida circunstancia de lo visible en el que hábitos y costumbres suelen poner en órbita la capacidad perceptiva de los seres humanos. Con el objetivo de ampliar ese universo, los movimientos de vanguardia de los primeros 50 años de este siglo realizaron experimentos extraordinarios en el terreno de la pintura y de la fotografía. El despliegue de nuevas formas retratísticas fue, sin duda, espectacular. Al hacer retratos o autorretratos, muchos de los artistas trabajaron la convicción de que era tras el rastro de las partes desconocidas e invisibles donde el fotógrafo y el pintor se encuentran con referentes insólitos.

En este retrato de Salvador Dalí que nos dejó Philippe Halsman, el espectador es colocado ante una composición retratística en que la

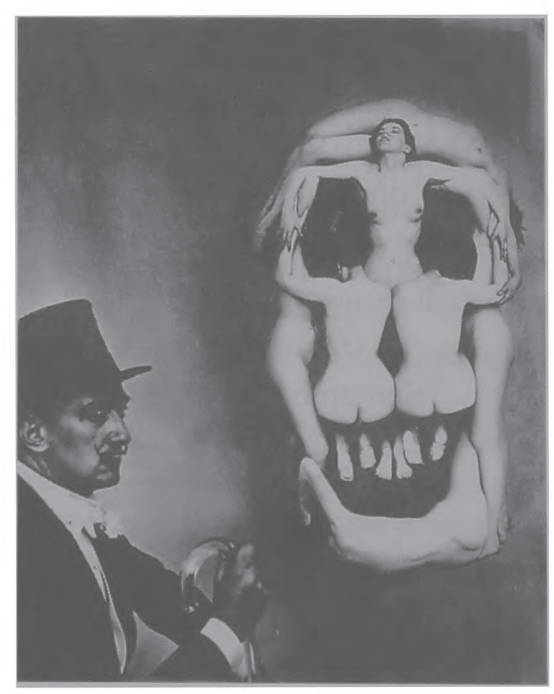

Signifieagóo $13 \cdot 114$ 
metáfora iconográfica conseguida por la combinación de varios cuerpos femeninos sirve, entre otras cosas, para "hacer visibles" rasgos del temperamento y del ingenio del pintor catalán. La disposición de los cuerpos configura la imagen de una calavera, pero, al mismo tiempo, expone a la mirada de quien contempla la fotografía gestos y actitudes que irradian erotismo.

En ese remolino de simultaneidades, la metáfora iconográfica activa los resortes de la pulsión de muerte al permitir que su presencia se haga notable a través de un intenso juego de intermitencias. Las imágenes son una cosa y otra, se confunden y su confusión suelta la chispa, la ráfaga de luz que ilumina, de repente, algo que nos era invisible, algo que tal vez tenga como referente el esbozo de bulto que nos acompaña desde tiempos inmemoriables, de un bulto que es, a la vez, parte de las entrañas y parte del cuerpo.

Además, las prácticas retratísticas del Surrealismo, sean pictóricas o fotográficas, mantienen con lo erótico una relación muy singular. La exposición que, con el título féminimasculin-Le sexe de l'art tuvo lugar, de 24 de octubre de 1995 a 12 de febrero de 1996, en el Centre nationale d 'art et de culture Georges Pompidou, consiguió reunir un impresionante conjunto de obras en las que esa relación es patente. El sinnúmero de procedimientos utilizados en ellas no sólo evidencia el ingenio de los artistas, sino que prueba también la pujante expansión de la substancia de que están formadas las figuras eróticas. Los objetos relacionados para construir las metáforas son de índoles muy diversas, pero, en general, portadores de marcas fetichistas.

En ese mar de imágenes que se preservan en el hermoso catálogo de la exposición publicado por la editora Gallimard, me detendré, para no desviarme de mis propósitos, en aquéllas que tienen como protognista el cuerpo, porque, como dice Marina Warner al centrar su atención en las connotaciones del pelo, el cuerpo, inagotable fuente de mitos, 
ne produit pas une gamme de symboles immuables, figés dans une structure rigide. S'agissant d'un matériau aussi riche et complexe que le cheveu, il ne saurait être question de revenir sur quelque vérité fondamentale ou signification donnée, de type archétypal. Reste que les symboles naturels présentent - ainsi que Mary Douglas l'a analysé - une structure de relations issues de leurs propriétés materielles2. Le corps, avec ses différentes composantes, ses sécrétions, ses substances, offre une sorte d'alphabet ou de système chromatique dont les modèles d'agencement, bien que quasiment infinis, forment néanmoins des groupes et des figures reconnaissables de la même façon que les accords ou certains syntagmes du langage (Warner, 1995, p. 303).

Pensando, pues, en los acordes y en los sintagmas de tal lenguaje, deseo detenerme, motivado por su desconcertante cartografia, en este Desnudo que Edward Weston obtuvo con el auxilio de cuidadoso

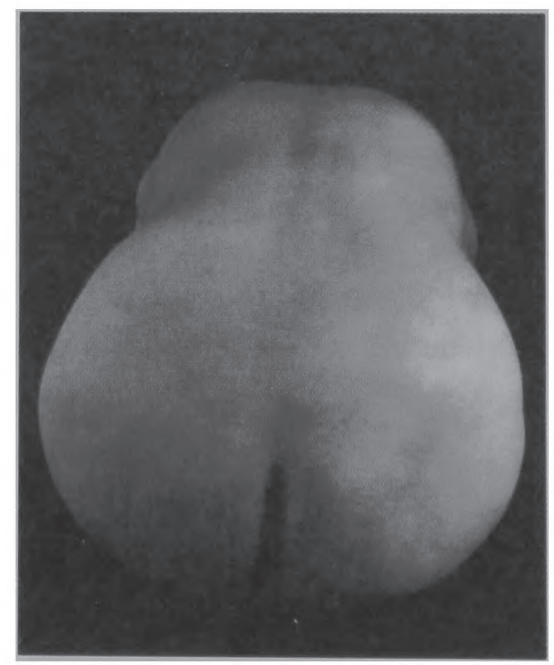

Significação $13 \cdot 116$ 
encuadramiento en leve picado. A primera vista, el torso femenino ahí representado crea la sensación de que el espectador tiene ante los ojos una metáfora visual cuyo término de llegada podría ser una fruta: una pera, por ejemplo. Pero, ése es mi caso, luego el espectador presiente que detrás de esta metáfora in absentia disyunta se esconde el cosquilleo de otra figura. A quien conozca las convulsiones poéticas del Surrealismo no le será difícil, pienso, tirarse desde la configuración metafórica de la mujer-fruto para caer en los dominios que se entrevén desde la metáfora instituida a partir del instante en que se percibe la relación torso-pene, o sea, a partir del instante en que nuestra mirada atina con la sutil conformación de una metáfora in praesentia conjunta.

En la poética surrealista, el tropo resultante del entrelazamiento de esos dos tipos de metáforas tal vez sea uno de los trazos más característicos del vanguardismo de este movimiento artístisco. Aparece con extraña insistencia en las fotos de Man Ray, Jacques-André Boiffard, Léo Malet, André Kertészt, Hans Nellmer, Roger Parry y Lee Miller, para citar tan sólo nombres bien conocidos. En la pintura, las obras de Magritte, Ernst y Dalí son las más representativas. Apesar de sus muchas variables, esta conformación metafórica presenta algunos rasgos permanentes, pues, en tanto representante de cosa, siempre o casi siempre se refiere a analogías antagónicas y a una imagen preedípica ${ }^{36}$ de la que es necesario encontrar una forma significante para posibilitar su manifestación. La primera característica es más perceptible en las metáforas por producto lógico: una parte del cuerpo sustituye a otra, un órgano sexual se

36. Al inicio de su estudio de la muñecas de Bellmer, Hal Foster se refiere, en cierto sentido y aunque sus propósitos no sean exactamente los mismos que se persiguen en mi trabajo, a esos dos rasgos cuando dice: "In Die Puppe he speaks of the first doll as a way to recover 'the enchanted garden' of childhood, a familiar trope for a pre-Oedipical moment before any impression of castration. Moreover, in Petite anatomie de I'inconsnéntphysique, ou I'Anatomie de ;'image (1957), he locates desire specifically in the bodily detail, which is only real for him if desire renders it artificial - that is, if it is fetishized, sexualy displaced and libidinally overvalued. Such is the 'monstrous dictionary of the image'. Bellmer writes, 'a dictionary of analogues-antagonisms' " (FOSTER, 1997, p. 103). 
transforma en su contrario. Con respecto a la segunda, la significación parece tener una polisemia más amplia. La extensión expresiva que funciona como representante de cosa se impregna del humus de lo animal o del protonarcisismo fetal.

De cualquier manera y aun admitiendo que la multitud de partículas semánticas que integran el universo de esos rasgos permite la formación de un sinnúmero de combinatorias sememáticas, forzoso es reconocer que todas esas formas del contenido tienen como substancia lo que, a falta de una denominación más precisa, se puede llamar ideología surrealista. Una ideología que, sin duda, dispone en primer plano las formas del erotismo y de la ominosidad. Todo eso quiere decir que, en el fondo, la convulsión poética de los artistas del Surrealismo nace de un complejo juego cuya regla principal se infiere de la inversión de las imágenes y de las cosas que el sentido común de los seres humanos confunde con la "realidad" Trastornar, por tanto, el orden establecido, "girar" las imágenes, tal cual, en La puberté proche, hace Max Ernst con una foto - a lo que parece de Gala desnuda extendida en un sofá - que le habría dado Salvador Dalí. Rosalind Krauss describe así el proceso:

Pero más tarde gira la fotografía y, por ende, también el cuerpo; de manera que, con una rotación de 90 grados, vuelve nuevamente a pender, como una vertical ingrávida suspendida en un extraño material, el éter aterciopelado del guache que cubre la superficie de la fotografía como una piel tersa. Erecto y sin cabeza, el desnudo aparece dentro de este campo espeso convertido en la mismísima imagen del falo, esto es, transformado en sujeto y objeto de esa inconfundible fantasía edípica, tener y ser el sexo de la madre (KRAUSS, 1997, p. 57).

Significaqáo $13 \cdot 118$ 
Sólo que, en el caso de la foto de Edward Weston aquí reproducida, las inversiones y transtornos generan un representante de cosa cuya referencialidad no es, en principio, edípica. La intermitencia de las imágenes del torso y del pene crea, de algún modo, un instante de peripateia que permite que el espectador "vea" el referente preedípico a que tal configuración visual subrepticiamente se refiere. Esa extensión significante, con sus acordes y sintagmas, remite a una configuración que tiene por probable contenido el universo de significado de que nos habla Pacteau en este pasaje:

The androgynous-looking figure presents me with an impossibility, that of the erasure of difference, that very difference which constructs me as a subject. From the instant my biological sex is determined, my identify is defined in difference - I am either a boy or a girl. I shall consequently take up my position in society on one side of the sexual divide, behave according to the genderized codes, reaffirm the difference. The androgynous "position" represents a denial, or a transgression, of the rigid gender divide, and as such implies a threat to our given identity and to the system of social roles which define us. How can I reconcile the observation of threat with that of desire? Desire here has to be understood in a particular psychoanalytic acceptance of the term: an unconscious wish, indissolubly attached to memmory traces, evoked though certain stimuli and associations; desire born out of the first loss of the mother's breast - and whose subsequent demands may require the hallucinatory reproduction of the traces of those earliest perceptions which have become the signifiers 
of lost primal satisfactions. In this context the wish

corrélative to the androgynous fantasy would be

attached to archaic memories of early chilhood; the

disavowal of sexual différence therefore represents

the fantasized re-enactment of an early pleasurable

perception [...] (PACTEAU, 1989, p. 63).

En cuanto arquetipo errante, el andrógino vaga por las regiones sombrías del ser. Atraviesa los espacios interiores y, siendo una especie de jinete de los caballos del deseo, su efigie, es, en verdad, un referente imposible, un referente que fascinó, desde siempre, a los surrealistas. De tal manera ese hechizo es entrañable en los seres humanos de las más diversas culturas que resulta asombroso constatar que la androginia, en el sentir de millones de personas, se centra en el corazón, en donde las palabras no se traducen, sino que se sienten como se deslizan y se internan en el espacio que hay entre ellas.

Las metáforas animalescas de Les Chants de Maldoror, óbra tan admirada por los surrealistas, ${ }^{37}$ expresan, en lo que tienen de poesía profunda, un incontrolable deseo de androginia. El viento, ${ }^{38}$ presente en

37. Rosalind Krauss no se refiere directamente a la androginia en este pasaje que transcribo a continuación, mas destaca: "Qui plus et depuis la découverte enthusiaste du bestiaire fantastique de Lautréamont, Les Chants de Maldoror, publié en 1869, l'exploration de la notion d'animalité humaine était devenue un des lieux commun du surréalisme. Mais ce serait ignorer le processus exact de ce comme si: sa réalisation grâce à la syntaxe de l'emprise de la caméra sur son objet, son renversement du corps, sa prise d'angle ascendante, son raccourci et son massicotage extrêmes, de sorte que cette expérience particulière de l'humain/animal se produit au moyen d'un procédé spécifiquement spatial, procédé qui suggère le vertige dont parle Dali, qui projette l'image dans le domaine du tournoiement et est une démonstration de la chute. Le corps ne peut être vu comme humain puisqu'il est redevenu animal" (Krauss, 1985, p. 60).

38. "Écoute bien ce que je te dis: dirige tes talons en arrière et non en avant, comme les yeux d'un fils que se détourne respectueusement de la contemplation auguste de la face maternelle; ou, plutôto, comme un angle à perte de vue de grues frileuses méditant beaucoup, qui, pendant l'hiver, vole puissamment à travers le silence, toutes voiles tendues, vers un point déterminé de l'horizon, d'où tout à coup part un vent étrange et fort, précurseur de la tempête" (LAUTRÉAMONT, 1987, p. 9-10).

Significação $13 \cdot 120$ 
muchas de ellas, esboza rumbos, atraviesa fronteras - yo creo que las ignora por completo - y sólo descansa de tántos viajes solitarios en la unidad andrógina de lo cósmico. Quizás por eso no extraña que Gastón Bachelard (1958, p. 6-15) se entregue a la explicación de la poética de Lautrémont a partir de lo que él denomina complejo de la vida animal y nos diga, ya en el primer capítulo, que las formas animales que aparecen en la obra del gran poeta estén mal dibujadas. No son formas reproducidas, sino producidas, esto es, son formas inducidas por las acciones, ya que una acción crea su forma, así como el obrero inventa su herramienta. En ese sentido, creo que el encuadre ${ }^{39}$ y el ángulo de cámara son, en innumerables fotos surrealistas, acciones que inducen las formas y son, asimismo, responsables por el complejo de la vida animal$^{40}$ que emana de las cartografías del cuerpo forjadas por Man Ray, Salvador Dalí, René Magritte y tantos otros.

Desde esa perspectiva, la forma andrógina hay que inventarla también si se quiere que ella sea auténtica, pues nos es auténtica la forma del andrógino reproducida según las indicaciones que fornecen las descripciones literarias. El complejo de animalidad se manifiesta através de acciones viscerales, como viscerales son las metáforas de la foto de Edward Weston. Me refiero al movimiento que los órganos internos realizan en las cavidades pectoral y abdominal del cuerpo. ${ }^{41}$ Movimientos en

39. 'Le cadrage, de même que le redoublement des phonèmes dans 'papa', est 'significatif d'un signifiant', le signal d'une brèche ouverte dans la percpeüon simultanée du réel, d'une rupture débouchant sur le sucessif. Le cadrage est toujours ressenti comme un hiatus dans le continuus du réel. Mais, chez les surréalistes, il assume un rôle considérable et se déchiffre lui-même comme un signe - un signe vide, il est vrai, mais néanmoins un facteur intégral dans le calcul du sens" (Krauss, 1985a, p. 35).

40. Recuérdese la famosa foto de Man Ray hecha en contrapicado en que el tórax de un ser humano se transforma en la figura de un minotauro y, también, las famosas tapas de la revista Minotaure. Las fotos de Brassai son, a lo que parece, las que explotan la animalidad en la corporeidad humana de manera más explicita.

41. Creo que muchas de las metáforas animalescas elaborad as por Lautrémont tienen como término de llegada referentes de los visceral: “Je me connais à lire l'âge dans les lignes 
principio invisibles, pero que las cartografías metafóricas proyectadas por la tecnología ofrecen a los ojos con increíble nitidez. No se puede olvidar que tales configuraciones sirvieron para estudiar aspectos fundamentales de la narrativa, como es el caso de la relación establecida porsemióticos rusos entre alimentación/defecación y funciones narrativas. Quiero decir, por consiguiente, que las metáforas de la foto de Weston crean un constante vaivén $\mathrm{y}$, además de eso, instauran una pluralidad retórica, una pluralidad que alude a los recónditos dominios de la androginia. ${ }^{42}$

En suma, la extensión significante construida por Weston en su fotografía crea un representante de cosa en el que se imbrican, como ya

Herm afrodita

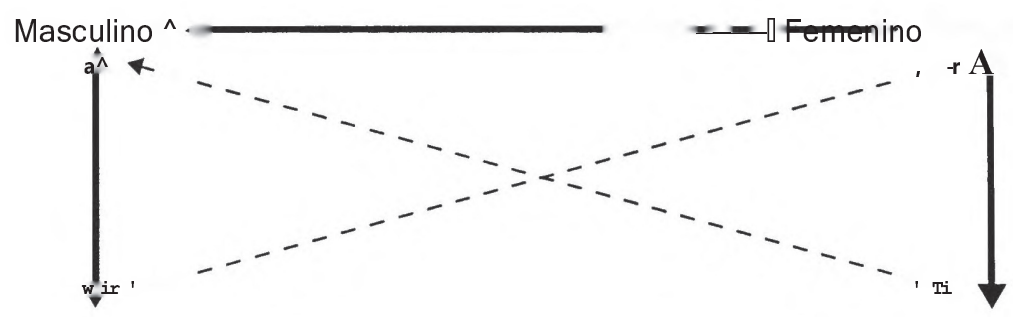

No masculino ${ }^{\wedge}$

[. No femenino

Andrógino

se ha visto, dos tipos metáfora que tienen por referente lo andrógino, o sea, el término neutro que, en el esquema transcrito, ocupa un punto de

physyognomoniques du front: il a seize ans el quatre mois! Il est beau comme la rétractilité des serres des oiseaux rapaces; ou encore, comme l'incertitude des mouvements musculaires dans les plaies des parties molles de la région cervicale postérieure [...]" (LAUTRÉMONT, 1987, p. 392).

42. "Le soin que prend l'auteur sacré d'utiliser le pluriel n'est-il pas une allusion à la tradition antérieure de Pandrogyne' que commémorent à l'envi les mythologies, le Banquet de Platon et l'héritage alchimique? Sans parle, évidemment, du tantasme que chacun nourrit en secret dans l'intimitpe de son désir!” (Bril, 1994, p. 205).

Significaçcīo $13 \cdot 122$ 
la tensividad existente entre lo no maculino y lo no femenino. Me parece, por consiguente, que el retrato surrealista, una de sus especies al menos, genera un representante de cosa a través de una metáfora iconográfica cuya figurativización, con todo lo que tal proceso significa, instituye, sin duda, un doble juego: el de Eco y el de Narciso. Aquellos semas viajeros a los que me refería cuando mencionaba lo remoto de su origen se reúnen, pues, para formar combinatorias de la figuratividad profunda, de la figuratividad de una corporeidad simbólica cuya cartografía esboza acordes y sintagmas de la imagen perseguida por Narciso, de la imagen, en fin, de un cuerpo primario, primordial y preedípico, que la poesía transformó en mundo.

Considerando, por tanto, que el tropo de esa extensión significante instituye un fenómeno de semiosis en el que se condensan conocimientos de la ideología surrealista - obsérvese que no se toma como referente el hermafrodita -, me parece defensable la hipótesis de que tal figura se presenta asumiendo todas las características de una metáfora epistemológica, esto es, de una metáfora que refleja, para usar las palabras de Zavala (1991, p. 193), "el modo en que la ciencia y la cultura de una época comprenden la realidad"

\section{Bibliografía}

AntoIne, Veronique. 1995. Artists face to face. New York: Barron 's.

BACHELARD, Gastón. 1978. Lautrémont. París: José Corti.

BARTHES, Roland. 1986. Arcimboldo o El retórico y el mago. In: Lo Obvio y lo Obtuso. Barcelona: Paidós.

BRETON, André. 1985. Le Surréalisme et la peinture. París: Gallimard. BRIL, Jacques. 1994. Petite fantasmagorie du corps. París: Éditions Payot \& Rivage.

BRYSON, Norman. 1990. Looking at the ovedooked. Four essays on still 
life painting. Cambridge: Harvard University Press.

Burgin, Victor. 1 989. Diderot. Barthes, Vertigo. In : Formations of fantasy. New York: Routledge.

CUNNAR, Eugene R. 1990. The viewer's share: Three sectarian readings of Vermeer 's Woman with a Balance. Exemplaria 2, p. 501-31 Dorra, Raúl. 1997. Entre la voz y la letra. Puebla: PlazayValdés Editores. DUBOIS, Philippe. 1988. L 'Acte photographique. Bruxelles: Editions Labor. DUBOIS, Philippe y Winkin, Yves. 1988. Rhétorique du corps. Bruxelles: Éditions Universitaires.

FABBRI, Paolo. 1987 Le passioni del volto. In: EffettoArcimboldo. Milano: Bompiani.

FALChETTA, Piero. 1987 Antologia di testi del XX secolo. In: Effetto Arcimboldo. Milano: Bompiani.

FiLÓSTRATO el VIEJO. 1 993. Imàgenes. Madrid: Ediciones Siruela. FONTANILLE, Jacques. 1995. Sémiotique du visible. Paris: Puf. FOSTER, Hal. 1996. The return of the real. Cambridge: MIT. . 1997 Compulsive beauty. 2 ed. Cambridge: MIT

FREUD, Sigmund. 1992. Lo ominoso. In: Obras completas, XVII. Buenos Aires: Amorrortu editores.

Greimas, A. J. 1966. Sémantique structurale. Paris: Larousse. 1973. En torno al sentido. Ensayos semióticos. Madrid: Fragua. 1987 De l'imperfection. Périgueux: Fanlac. GROUPE p. 1970. Rhétorique générale. Paris: Larousse. 1992. Traité du signe Visuel. Pour une rhétorique de I'image. Paris: Seuil. Hall, Edward T. 1976. Beyond culture. New York: Anchor Press/ Doubleday. Hulten, Pontus. 1987 Thre different kinds of interpretation. In: The Arcimboldo Effect. Londres: Thames and Hudson. Jones, Roger S. 1983. Physic as metaphor. New York: Meridian Books.

Significação $13 \cdot 124$ 
KaUfman, Thomas DaCosta. 1987 Le allégorie e i loro significati. In. Effetto Arcimboldo. Milano: Bompiani.

Krauss, Rosalind. 1985. Corpus delicti. In: Explosante-fixe: phographie et surréalisme. Paris: Centre Pompidou.

KRAUSS, Rosalind. 1985a. La photographie au service du Surréalisme. In: Explosante-fixe: photographie et surréalisme. Paris: Centre Pompidou. 1997 El inconsciente óptico. Madrid: Tecnos.

Landowski, Eric. 1989. La société réfléchie. Paris: Seuil.

LautrÉMONT. 1987 Les chants de Maldoror Paris: Bibliothèque Lattès.

Le BRETON, David. 1995. Antropología del cuerpo y modernidad. Buenos Aires: Nueva Visión.

LIGHTBOWN, Ronald. 1989 Sandro Boticelli. Life and work. Londres: Abbeville Press Publishers.

LÓPEZ-Rey, José. 1996. Velázquez. Painter of painters. Londres: Taschem. Lyotard, J-F 1974. Discours, figure. Paris: Editions Klincksieck.

Montias, John Michael. 1989. Vermeer and his Milieu: a web of social history. Princeton: Princeton University.

Odin, Roger. 1990. Cinéma et production de sens. Paris: Armand Colin.

PACTEAU, Francette. 1 989. The impossible referent: representations of the androgyne. In: Formations of fantasy. New York: Routledge.

PANOFSKY, Erwin. 1990. Le Titien. Questions d'lconologie. Paris: Fiazan.

Peñuela CañIzal, Eduardo. 1992. La metáfora visual. Anàlisi, 14. Barcelona: UAB.

Saint-Martin, Fernande. 1997 Esthétique et psychanalyse. L'Imagem du plein et l'image du flou. Visio, v.l, $\mathrm{n}^{\circ} 3$. Montréal: Université du Québec.

Scharf, Aaron. 1994. Arte y fotografía. Madrid: Alianza Editorial.

Schneider, Norbert. 1994. The art of the portrait. Masterpieces ofeuropean portrait-painting 1420-1670. Londres: Taschen.

Silva, Ignááo Assis. 1995. Figurativização e metamorfose. São Paulo: UNESP. 
SONESSON, Göran. 1997 Approches to the lifeworld core of pictorial rhetoric. Visio, v.l, $n^{\circ}$ 3. Montréal: Université du Québec.

SYLVESTER. David. 1992. Magritte. Londres: Thames and Hudson.

WARNER, Marina. 1995. Le vil et le vigoureux, la toison et le poil: des cheveux et de leur langage. In: Féminimasculin-le sexe de l'art. Paris: Gallimard.

WHEELLOCK, Arthur K. 1995a. Vermeer and the art of painting. New Haven: Yale University. . 1995. Dutch painting of the seventeenth century

Cambridge: University Press.

WRIGTH, Christopher. 1976. Vermeer. Londres: Oresko Books.

ZAVALA, Iris M. 1991. La posmodernidad y Mijail Bajtin. Madrid: Espasa Calpe. 